Article

\title{
Sustainable complete streets design criteria and case study in Naples, Italy
}

\author{
Alfonso Montella ${ }^{1}$, Salvatore Chiaradonna ${ }^{2}$, Alessandro Claudi de Saint Mihiel ${ }^{3}$, Gord \\ Lovegrove $^{4}$, and Pietro Nunziante ${ }^{5, *}$ \\ 1 University of Naples Federico II - Department of Civil, Architectural and Environmental Engineering; \\ alfonso.montella@unina.it \\ 2 University of Naples Federico II - Department of Civil, Architectural and Environmental Engineering; \\ salvatorechiaradonna@alice.it \\ 3 University of British Columbia, Okanagan - School of Engineering; gord.lovegrove@ubc.ca \\ 4 University of Naples Federico II - Department of Architecture; alessandro.claudi@unina.it \\ 5 University of Naples Federico II - Department of Architecture; pietro.nunziante@unina.it \\ * Correspondence: alfonso.montella@unina.it; Tel.: +39-3389996765 (IT)
}

\begin{abstract}
Background: A growing number of communities are re-discovering the value of their streets as important public spaces for many aspects of daily life, thus creating the need for a transformation in the quality of streets. An emerging concept is to accommodate all users of the transportation system, a concept that has been labelled 'complete streets'. (2) Methods: In this paper, we present sustainable complete streets design criteria that integrate complete streets by adding in socio-environmental design criteria related to aesthetics, environment, liveability, and safety. (3) Results: Proposed design criteria provide a street network which provides improvements in aesthetics, to recover historical urban character and realize historical area planning goals; environment, to increase permeable surfaces, reduce the heat island, and absorb traffic-related air pollution; liveability, to create a public space destination in the urban landscape; and safety, to improve the safety of all road users. and (4) Conclusions: The case study of the urban rehabilitation of the "Mostra d'Oltremare" area and of its cultural and architectural assets in Naples, Italy, highlights the practical application of the proposed criteria and the possibility of using these criteria in other urban contexts.
\end{abstract}

Keywords: Urban streets; Aesthetics; Environment; Liveability; Safety; Vulnerable road users.

\section{Introduction}

In this paper, we present sustainable complete streets design criteria that integrate and build on the concept of complete streets with the concept of socio-environmental design criteria related to aesthetics, environment, liveability, and safety. The motivation behind adding on these socioenvironmental design criteria are set out in this introduction, followed by a description of the recommended criteria.

A growing number of communities are re-discovering the value of their streets as important public spaces for many aspects of daily life, thus creating the need for a transformation in the quality of streets. People need streets that are safe to cross or walk along, offer places to meet, and have a vibrant mix of retail. And more people must be able to walk and ride bicycles in their neighbourhoods, as communities pursue more sustainable development and lifestyle patterns. As a result, an increasing number of cities are looking to modify the way they design their streets. Furthermore, there is a need for flexibility in applying current design guidelines and the use of creative design in addressing site specific project needs [1]. In North America, an emerging concept is to accommodate all users of the transportation system, be they pedestrians, bicyclists, public transit users, or motor vehicle drivers and passengers, a concept that has been variously labelled 'complete streets' and 'walkable thoroughfares' [2-8]. 
At the same time as communities re-discover streets as public spaces and complete streets design principles, they are also realizing that street design significantly impacts the transport and land use system and overall community sustainability. It has long been understood that how we design our communities impacts the demand for travel and the choice of travel mode [9]. Resultant travel demand in turn impacts non-renewable energy consumption, pollutant and greenhouse gas emissions, obesity, congestion, collisions, and other factors that impact community sustainability [10]. Therefore, it is of critical importance that all street designs and street reconstruction projects, including those that follow complete streets design principles, seek to also enhance community sustainability.

Moreover, it is proposed that street design criteria meant to enhance community sustainability should complement, and build on, complete streets design principles. For example, complete streets design principles include social (i.e., safety, equity) and economic (i.e., efficient) considerations. Adding environmental design considerations toward community sustainability would complement this complete streets design. For example, creating a destination for pedestrians and cyclists to shop, socialize, and rest, would transform and enhance a street previously occupied by automobiles, more so than just designing it as a complete street to travel through [8]. Moreover, this form of communitysustainability-oriented retrofit of an existing street, and building on complete streets design principles, could be a catalyst for adjacent land use change and increased private investment.

To expand this concept building on these social and economic complete streets criteria, sustainable complete streets design criteria are proposed, related to other social and environmental aspects, including aesthetics, environment, liveability, and sustainable road safety planning. By adding environmental and enhanced social design considerations, these sustainable complete streets design guidelines can be employed in retrofits of urban areas and help to enhance overall community sustainability.

Improvement of the pedestrian, cycle and road network represents an opportunity for the morphological rehabilitation of significant parts of the city. It is a chance for innovation and rehabilitation of innovative, smart, efficient, inclusive, resilient implementation and management methods. The future challenge is to make sustainable and complete streets designs that promote more sustainable communities in areas where mobility has historically been a primary concern. Moreover, in European cities this transformation is often complicated by a historical context full of constraints not easily correctable.

To address these emerging issues, the purpose of this paper is twofold: (1) to present sustainable street design criteria that complement and build on complete streets design criteria, that taken together accommodate all users while also meeting health, safety, and environment priorities; and (2) to present an Italian case study to highlight practical application of these sets of criteria, which taken together we will label as 'sustainable complete streets' design criteria.

\section{Materials and Methods}

\subsection{Overview}

The main goal of the proposed sustainable complete streets design criteria is to provide a high quality (liveable) land use and transport system adapted to contemporary requirements for the social, economic, and environmental priorities of urban mobility and access, including the following principles:

- Reduce traffic crashes and injuries, of both motorized and vulnerable road users;

- Reduce motorized traffic volume and speed;

- Increase pedestrian, bicyclist and public transport traffic volume;

- Improve the quality of urban landscape space, for example its aesthetics and functional ambiance;

- Increase 'green space' opportunities for pedestrians and cyclists to stop, shop, and socialize;

- Reduce non-renewable energy use and its associated air pollution emissions; and 
- $\quad$ Reduce nuisances due to traffic noise and urban heat island effects.

In many respects, this design approach is known as 'eco-design' [11, 12], since special environmental emphasis is given to reduce heat island effects and absorb air pollution caused by vehicular traffic. Indeed, streets are important public spaces for many aspects of daily life and have significant effects on the liveability of the city. However, the traditional road design standards and guidelines do not give enough consideration to these essential issues. The additional principles proposed above introduce environmental and architectural restoration design considerations to recover urban character lost in an historical evolution characterized by lack of conscious, coordinated urban planning. The vision is to create a road environment homogeneous as regards to the choice of materials, colours, lighting, and treatment of green spaces, for the health and safety of people, and protection and preservation of the environment. Moreover, this vision must live within the overarching community values placed on their historical built environment that deserve to be included in the design of public spaces.

Table 1 is a list of general and specific criteria to be addressed, highlighting how sustainable complete streets criteria integrate with complete streets criteria. A discussion of each criteria follows. 
Table 1. Synthesis of the sustainable complete streets design criteria.

\begin{tabular}{|c|c|}
\hline $\begin{array}{l}\text { General } \\
\text { Criteria } \\
\text { (section \#) } \\
\end{array}$ & $\begin{array}{l}\text { Specific } \\
\text { criteria }\end{array}$ \\
\hline $\begin{array}{l}\text { Aesthetics } \\
(2.2)\end{array}$ & $\begin{array}{l}\text { A1 Enhancement of the urban environment } \\
\text { to recover historical urban character and } \\
\text { realize historical area planning goals } \\
\text { A2 Integration of materials, colours, } \\
\text { lighting, and treatment of green spaces } \\
\text { A3 Durable materials }\end{array}$ \\
\hline \multirow{3}{*}{$\begin{array}{l}\text { Environment } \\
(2.3)\end{array}$} & E1 Eco-design \\
\hline & E2 Planting and trees \\
\hline & $\begin{array}{l}\text { E3 Reduction of traffic-related air pollution } \\
\text { and noise }\end{array}$ \\
\hline $\begin{array}{l}\text { Liveability } \\
(2.4)\end{array}$ & $\begin{array}{l}\text { L1 Usability and comfort of the public } \\
\text { outdoor space system }\end{array}$ \\
\hline
\end{tabular}

\section{Integration with \\ Complete Streets criteria}

Full integration between street design and the planning for redevelopment of the public space

Sustainable approach to integrate the street design and the built environment

Requirements for the use of durable pavements, markings, signs, lightings, and street furniture to reduce the unpleasantness caused by deterioration during its life cycle Life Cycle Design and Life Cycle Assessment of building products

Use of green space to form a natural filter and buffer from pollutant gases, dust, and noise as well as to reduce urban heat islands Strengthening of the community system design approach to reduce auto trips and promote healthier active transport choices

Attention to the functional and environmental design aspects of public space to ensure that end user and lifecycle impacts are addressed with a view towards sustainability

L2 Creation of a public space destination in the urban landscape which affects activities and social relations

Coordination between urban planners, landscape architects, and transportation engineers in developing the design of the street as a public space destination in the urban landscape

\begin{tabular}{|c|c|c|}
\hline \multirow[t]{9}{*}{$\begin{array}{l}\text { Safety } \\
(2.5)\end{array}$} & S1 Road safety inspections & $\begin{array}{l}\text { Introduction of formal road safety } \\
\text { inspections of the existing network }\end{array}$ \\
\hline & S2 Road safety audits & $\begin{array}{l}\text { Introduction of formal road safety audit of } \\
\text { all plans and designs prior to construction }\end{array}$ \\
\hline & $\begin{array}{l}\text { S3 SMARTer Growth (Fused Grid) } \\
\text { neighbourhood pattern }\end{array}$ & $\begin{array}{l}\text { Safe system design of community land use } \\
\text { \& transport to reduce auto use \& speeding }\end{array}$ \\
\hline & S4 Safe pedestrian routes and crosswalks & $\begin{array}{l}\text { Specific criteria to provide a comprehensive, } \\
\text { safe pedestrian route network }\end{array}$ \\
\hline & S5 Safe cycle routes and crossings & $\begin{array}{l}\text { Specific criteria to provide a comprehensive, } \\
\text { safe, and continuous cycle route network }\end{array}$ \\
\hline & S6 Sight distance & $\begin{array}{l}\text { Explicit consideration of visibility from the } \\
\text { perspective of all roadway users }\end{array}$ \\
\hline & S7 Transit and pedestrian accessibility & Link between accessibility and safety \\
\hline & S8 Traffic control devices & $\begin{array}{l}\text { High-performance traffic control devices as } \\
\text { explicit safety criterion (e.g., roundabouts) }\end{array}$ \\
\hline & S9 Lighting & $\begin{array}{l}\text { Use of high-performance lighting as explicit } \\
\text { safety criterion (e.g. solar power LEDs) }\end{array}$ \\
\hline
\end{tabular}




\subsection{Aesthetics}

Roads are an important part of the very complex land use and transport system, which hosts many functions that facilitate and characterize social and economic activities. At the same time, roads facilitate social encounters and the specific space of a whole range of other activities. The quality of urban life - the space designed for pedestrians, cyclists, and bus traffic together with that of private and commercial vehicles - is one of the major urban street design issues of our time. Collectively, we refer to it as aesthetics or functional ambiance [13].

Planning the redevelopment of public space must begin with defining the principles that will relate to the quality of the open and public areas. Historically, streets and public squares were designed for symbolic representations of government and/or monarchy power; see for example Washington, D.C.; Paris, France; and Naples, Italy. Streets were defined by building facades and facing activities. Architectural design defined the quality of a building and an urban landscape surrounding it. With most cities now built, the emerging practise has been to search for open spaces to retrofit and thereby help improve the quality and ambiance of city life. Today, increased population and traffic density require that streets and squares be designed to support civic uses and behaviours essential to contemporary urban lifestyles. Streets are defined as a means of connection between city destinations. This evolution in street functional ambiance, from a local support space to a connector of disparate non-local functions, has frustrated local planning and built-environment design. Moreover, the volume and speed of traffic has increased in areas historically designed for much lower traffic demands, and eroded the intrinsic benefits of restorative, resting and/or green spaces on streets. The rehabilitation of public space, including complete streets re-design, provides an opportunity for adding in a sustainability-oriented, eco-design approach to project design. For example, it might include integrating durable materials, colours, lighting, green space and ecology into the project. However, steps toward realizing this opportunity must deal with the problems that the unruly urban phenomenon of traffic proliferation has generated. No literature demonstrating this eco-design retrofit approach has been found. Designs to not only increase cycling and walking and social spaces, but to also enhance an urban environment functional ambiance is part of an approach now widely accepted, that has yet to be well defined around the world.

\subsection{Environment}

In 1986, the introduction of the principle of sustainability by the United Nations [14] initiated a paradigm shift in design rules and practices. Unfortunately, that shift towards incorporating sustainability principles in design criteria has been slow to take hold in the project design domain, resulting in the built form seen along many road corridors today. What is needed is a more unified approach to space planning, which has been identified by the term eco-design.

Eco-design [12] is based on the idea that any size and shape of the project has to deal with the environment, with the landscape and the environmental impact - the context within which the project is being designed. This strengthens the project's sustainability based on the ability to control the whole life-cycle of the project's impacts. The term eco-design, from the etymological and semantic standpoints, denotes two distinct meanings. First, it denotes attention to the impact of the design on the environment. Second, it speaks to a design economic, optimized, proportionate, and essential aimed at a particular utility, use or purpose. The root word "eco" comes directly from the concept of 
oikos, meaning house or dwelling. In Greek, this indicates the shelter from which we can derive the notion of the first human environment, its simpler and primitive cell.

There are designers who take the environmental issue as an opportunity to create services and infrastructure much less harmful than we have today, closer to a sense of compatibility. However, eco-design goes beyond compatibility, to the rational foundation of ecology, to the scientific principles that guide design choices that control all stages of the production chain and the consumption of inputs. It speaks to control of design and assessment of impacts over the entire life cycle of the design 'product'. This eco-design concept of sustainability-based design principles then leads to integration of policy, inputs, and production in their broadest sense, for example, to ensure green procurement, durability of materials, construction of green, choice of urban furniture, and high-performance lighting.

Green space can be used to form a natural barrier to pollutant gases, dust, and noise as well as to reduce urban heat islands. Also, through the choice of materials it is possible to reduce urban heat effects, such as choosing no-fines paving, and rough or smooth functional strips. As another example, through the road surface material treatment, results can be achieved towards speed reduction for safety and energy and resource savings, in both up front and long-term benefits. Moreover, reduction in maintenance costs (typically over half of a project's life-cycle costs), can be realized by careful choices of resources made at the design phase of the project.

\subsection{Liveability}

When talking about the design of more sustainable communities, public space considerations often dominate, and lead to urban liveability design discussions around such issues as: population density, mobility, infrastructure, and green space [15]. A common topic concerns the community's architectural image at both city-wide and local-area scales, which intersects via local sustainabilityoriented designs set within the characteristics of the broader reference context. For example, consider the relationship between buildings and their environment in broader contexts characterized by the presence of historically established features and activities. Urban planners and landscape architects must work with transportation engineers in also developing the design of the street as a public space destination in the urban landscape, not just as a thoroughfare, including how its physical elements affect activities and social relations in those two (local and city-wide) contexts.

These two non-engineering disciplines rightfully pay attention to public space in terms of:

- Ambiance, i.e. the conditions of usability, comfort and safety of the public outdoor space system, including its quantity and quality of green amenities; its environmental and ecological function; and, its coherent configuration; and,

- Function, highlighting the added value of high environmental performance in terms of efficiency, functionality, maintenance, durability and recyclability, including reduction of energy consumption at the urban and building scale; reduction of air, water, noise and visual pollution; and, mitigation of impacts generated by infrastructure systems.

The attention to these functional and environmental design aspects of public space helps to ensure that end user and lifecycle impacts are addressed with a view towards sustainability pedestrians and bicyclists; transit; parking; innovative technologies; renewable energy sources; and, integration of explicit (e.g., signs) and implicit (e.g., surface colouration) information and communications technologies. 
Beyond public space as a destination, road (re-)designs must also consider other fundamental functions, including that of moving people. Road network rehabilitation is an opportunity for a wider urban and environmental regeneration, but only where it is possible to have an integrated, team approach within the fields of environment, engineering, and planning. It means an integrated vision of design measures aimed at improving the quality of urban life, developing approaches that encourage public-private partnerships and involving a wider variety of stakeholders in the process of urban transformation than historically engaged. A diverse team for these projects in which complexity reigns is a strategic and success-critical resource to be cherished and supported. In this regard, it is strategically important to identify the most appropriate regulatory and administrative framework to implement the configured actions, not only checking their compatibility, but also proposing innovative and advanced solutions that best meet well-defined community values and visions.

\subsection{Safety}

Road safety improvement is a key objective all over the world. In 2010 the governments of the world declared 2011-2020 as the Decade of Action for Road Safety [16]. The 2030 Agenda for Sustainable Development, adopted by all United Nations Member States in 2015, provides a shared blueprint for peace and prosperity for people and the planet, now and into the future. At its heart are the 17 Sustainable Development Goals (SDGs), which are an urgent call for action by all countries. The SDG 3 Ensure healthy lives and promote well-being for all at all ages has defined a target related to road safety (target 3.6) "By 2020, halve the number of global deaths and injuries from road traffic accidents". The SDG 11 Make cities and human settlements inclusive, safe, resilient and sustainable has defined a target related to road safety (target 11.2) "By 2030, provide access to safe, affordable, accessible and sustainable transport systems for all, improving road safety, notably by expanding public transport, with special attention to the needs of those in vulnerable situations, women, children, persons with disabilities and older persons".

Lowering the number of road users' casualties is key to improving the overall performance of the transport system and to meet citizens' and companies' needs and expectations. Furthermore, more than half of fatalities are among vulnerable road users (VRUs) such as riders of, mopeds, pedestrians, cyclists, and motorcycles who represent an important challenge for road safety [17-20].

\subsubsection{Road safety inspections}

To improve safety of the existing network, the sustainable complete streets design criteria require routine safety inspections of the road network to identify potential hazards for all road users. These are assessed by measuring risk in relation to road features that may lead to future crashes, so that remedial treatments may be implemented before crashes happen according to a preventive and systemic approach to road safety [21-29]. Traditionally, safety improvements have been made only at hotspots after high number of crashes have occurred [30-36]. If only hotspots are treated, a large number of locations that can be expected to experience crashes in the future will remain untreated. Waiting for crashes to warrant actions carries a high price, as vulnerable road user crashes tend to be severe. Further, vulnerable road user crashes are generally widespread in the road network and under-reported, thus creating difficulties in hotspots identification based only on crash statistics. 


\subsubsection{Road safety audits}

The designers should investigate how the road environment is perceived, and ultimately utilized by each user group - pedestrians, cyclists, and motorists - and within each user group seniors, children, persons with disabilities, and, drivers of powered two wheelers, trucks, and cars. Several issues must be taken into account to ensure a safe design and it is not possible to define specific rules which guarantee a safe design. Standards are an important starting point with any road design. A designer should be familiar with the relevant standards, attempt to comply with them and be aware of where any standard cannot be achieved.

However, road designers will agree that standards do not guarantee safety, for the following reasons:

- Standards are often a minimum requirement and combining a series of minimums can leave no room for error, either on the part of the designer, the builder or the final users;

- Some situations require specific expert judgement, which might not be covered by standards;

- Individual road elements, designed to standard, may be quite safe in isolation but may, when combined with other standard elements, be unsafe; and,

- Driver errors, which contribute to $93 \%$ of all crashes [30], are bound to happen.

To properly take into account safety in all design stages, road safety audits should form an integral part of the design process at the draft design, detailed design, pre-opening and early operation stages [21]. A road safety audit is a formal examination of a future road or traffic project in which an independent, qualified team reports on the project's crash potential and safety performance [32]. Especially in urban areas, where there are often several competing objectives, a road safety audit ensures that safety is not overlooked in satisfying the many competing and complex objectives.

For urban area design processes, recommended principles to promote safer road use are provided below.

2.5.3 SMARTer Growth (Fused Grid) Neighborhoods - Land use development patterns, road networks, traffic volumes and speeds

Speeding, or travelling at speeds too high for the road environment, is considered to be a major factor contributing to road crashes [10,30,37-43]. Speeding is not simply driving faster than the speed limit; it is also driving within the speed limits but too fast for the prevailing weather, light, traffic and road conditions [44, 45]. Higher speed reduces available reaction time for drivers, and therefore creates a greater crash risk. Moreover, high collision speed is an aggravating factor in all crashes. Increased collision speed is associated with more severe consequences in terms of injury and material damage. Finally, reducing the volume of auto trips reduces exposure to crash risk.

A critical success factor to improve road safety in urban area is to control land use and road layouts that facilitate lower auto volumes, lower vehicle speeds, and lower conflict frequency between pedestrian/cyclist/vehicle. A system design community approach must be used that employs sustainable complete streets design principles, such as the SMARTer Growth (Fused Grid) neighbourhood design $[15,46]$. Extensive research has been published on this SMARTer Growth design, including many well-known Sustainable Road Safety design elements, such as:

- Roundabouts to reduce conflicts and crashes [30, 47-50];

- Traffic calming to lower speeds and short-cutting on local streets, and improve ped/bike safety;

- Continuous off-road ped/bike paths, such that biking across a neighbourhood is faster than driving; 
- Fewer road lanes of narrower width, with lower speed limits to address crossing distance and safety;

- Comprehensive bicycle and pedestrian route networks in accord with active travel demand and desire lines, integrated with compact, connected, and coordinated mixed land uses;

- Keep major mobility roads to perimeter one-way couplets containing service commercial blocks and controlled by roundabouts to reduce crossing risk and speeds;

- Interspersed public, open, green, restorative spaces throughout, such that no dwelling is longer than a one minute walk away from public open space, with a major central, car-free piazza that promotes both local and community-wide social interaction; and,

- Convenient, affordable, and accessible, high capacity public transit connecting this neighbourhood with major civic destinations.

\subsubsection{Pedestrian crosswalks}

Correct location of crosswalks reduces the risk of pedestrian crashes. Crosswalk location must be evaluated in relation to the road alignment and the desired pedestrian paths [28, 51]. Special emphasis should be given to interaction with parking, bicycle facilities, and bus stops along major roads. Indeed, the location of parking and bus stops may create significant increase in the pedestrian risk. In some circumstances, parking is allowed very close to the crosswalk, thus creating conflicts between pedestrians and vehicles. Use of bulb-outs to reduce interaction between pedestrians, bicycles, bus stops, and parked vehicles is strongly encouraged, such as that in the Dutch bicycle design guidelines [52]. Mid-block crosswalks located after bus stops may induce pedestrians to cross in front of the stopped bus, with a detrimental safety effect due to visibility of the pedestrian obscured by the bus.

Vehicles turning into and out of driveways may conflict with pedestrians walking along roadways. These conflicts can be reduced by consideration of pedestrians during the planning stages of a project, and by consolidating existing driveways. Removed driveways, or consolidation of driveways, can create space for other uses such as seating opportunities that might support adjacent business, or planting areas that provide buffers between vehicles and pedestrians.

In the case of wider roads, the presence of an adequate median 'block' and/or refuge should be carefully considered. Painted crosswalks aligned with pedestrian desire lines encourage pedestrians to cross within the crosswalk, where drivers are more likely to expect them.

\subsubsection{Pedestrian accessibility}

Pedestrian accessibility is another important safety issue, including mothers with baby strollers, seniors with walking aids, wheelchair users, visually impaired users, and tourists with luggage. Designers should consider the needs of all road users looking in detail to accessibility needs in each local context. Crosswalks that are not designed for accessibility have been associated with an increased number of people crossing away from the crosswalk, and not using the adjacent sidewalks at all, further degrading safety. Therefore, important accessibility issues to consider include:

- Presence and slope of curb ramps (crosswalks without ramps or with ramps with excessive grade are inaccessible for wheelchairs and baby carriages);

- Height of the curbs separating sidewalks from roads (excessive height poses significant problems of accessibility - falls and trips - to older people moving between parking and sidewalk);

- Rumble-strips and tactile-strips for visually-impaired pedestrians (ramps without preceding 'warning' strips are a significant hazard for blind people); and,

- Accessibility of median breaks (inaccessible breaks make the refuge ineffective). 


\subsubsection{Cycle routes}

Cyclists are legitimate users of the roadway and an integral part of the transportation system. Facilities for cyclists, preferably separated and continuous cycle tracks on both sides of the street, should be considered an integral part of any proper road planning process and network design [52]. The context of the road for a bicycle facility is a key element that should be considered in the design. Cyclists should be provided with a complete connected bicycle network, without any horizontal or vertical obstructions (temporary or permanent) along the facilities, that offers safe routes to destinations. The riding surface should be smooth, stable, free of debris, and with adequate drainage. In many cities, retrofitting to meet complete streets principles for bicycles is a difficult problem. A variety of innovative and effective design solutions is emerging in complete streets design guides, including: road diets, parallel 'bicycle-friendly' streets, and protected, buffered bicycle lanes [52-55].

\subsubsection{Sight distance}

Sight distance at urban intersections, cycle crossings, crosswalks, and even along sidewalks, is an important safety issue, as there are often obstacles that obstruct views and distract road users. Designers should evaluate visibility from the perspective of all roadway users, especially children and persons in wheelchairs, who may be lower to the ground. Sight lines between all users should be free from obstructions. Typical obstructions the designer must deal with carefully include: lighting and traffic signal posts, traffic control and bus stop posts, traffic signal controller kiosks, utility kiosks, newspaper kiosks, litter and recycling kiosks, and trees.

\subsubsection{Traffic control devices}

Traffic control devices are used extensively to regulate traffic, performing such functions as: to assign right-of-way, to indicate regulations in force, to warn motorists of hazards or regulatory controls ahead, and to guide traffic. There are generally two kinds of traffic control devices, signs and road markings, and their effectiveness is proportional to their clarity and visibility at any time of the day, in all seasons, and through each weather condition.

Road markings provide guidance for all road users by defining and delineating paths, and they also serve to alert road users of a pedestrian crossing point across roadways. They are a very effective way of providing guidance for motor vehicles and other road users (e.g., pedestrians, cyclists, public transport) as the markings are generally within the driver's field of view. The recommended high performance road markings are cold hardened, which provide for enhanced safety through effective daylight and night-time visibility, as measured by their luminance coefficient under diffuse illumination, and by retro-reflectivity (i.e., its ability to reflect light from a vehicle's headlights back to the driver's eye).

The safest road signs rely on the use of fluoro-reflective, micro-prismatic sheets. Fluoro-reflective micro-prismatic sheeting allows for:

- Greater daytime visibility;

- Greater night-time visibility;

- Greater visibility in the presence of light pollution (e.g. fog);

- Optimum angularity;

- Excellent visibility at wide entrance and observation angles; and,

- Greater visibility in critical conditions, such as rain, snow, cloudy weather, dawn, and dusk.

\subsubsection{Lighting}


Adequate lighting can improve visibility during the night-time, and this is particularly important for pedestrians and cyclists on or beside roads, as well as on off-road paths. Research results show that roadway lighting is usually associated with a reduction in night-time crashes [30, 56, 57]. Optimal lighting allows for improved perception and visibility of pedestrians, mutual sighting of vehicles, right perception of the road environment, and visibility of potential hazards.

The best safety and energy performances are provided if light-emitting diode (LED) sources are used. They are solid-state devices that produce blue light in combination with phosphors that convert some of the blue light to yellow light, with the resulting mixture appearing white. LEDs allow very long rated lives and good lumen maintenance. Some of the main advantages of LEDs are more uniform light distribution; lack of warm-up time; energy savings; reduction of the frequency of maintenance; directional light; reduced light pollution; environment-friendly characteristics; and, breakage and vibration resistance.

An important safety requirement is to provide adequate pedestrian visibility distance at crosswalks, defined as the distance at which a driver can see a pedestrian well enough to be able to respond appropriately to the pedestrian's presence. The greater the visibility distance the more time a driver will have to react to the pedestrian before a conflict occurs. In some instances, energy-saving, automated crosswalk lighting can cause hazards if triggered too late after a pedestrian is present. Overly delayed crosswalk lighting activation can restrict visibility of crossing pedestrians; therefore, the timing of lighting activation is a safety-critical design issue.

\section{Results}

\subsection{Overview}

The Campania Region in Italy was chosen as part of the EU's Regional Operational Programme framework to identify major projects in the fields of sustainable transport, environment, infrastructure, and tourism. On 28 $8^{\text {th }}$ March 2011, Resolution 122 of the Regional Council established several major projects in the city of Naples, including one project related to the urban rehabilitation of the "Mostra d'Oltremare" area and its cultural and architectural assets. The design of this urban rehabilitation has employed the principles and criteria of sustainably complete streets design, as summarized following.

The study area is characterised by the presence of important attractors: buildings of significant architectural value in the Overseas Exhibition, the university, and sports facilities. Taken together with major regional road and railway networks makes this area one of Naples main activity centres. Its urban development occurred mainly in the late 1920s and 1930s, and in 1936 Mussolini awarded Naples the Triennial Overseas Exhibition, in Italian referred to as the "Mostra d'Oltremare", or locally known as Mostra. Typical of Mussolini period architecture, Mostra contains a monumental centre, and was intended to be representative of the historical centre of a modern era city. Mostra is characterized by wide open spatial and environmental qualities, thanks to purposeful design of green and open spaces, which were intended to connect the two historical centres (i.e., Mostra and historical Naples). It remains of nostalgic importance for city life as the main centre for trade shows and sports events, as well as for the presence of numerous national research institutes, university departments, and government offices.

The urban context within which Mostra is situated (Figure 1) is complex, where over the past 70 years Naples has been impacted by a series of civic policy decisions that, in recent decades, have 
created major road traffic congestion problems. Only in recent years, Naples has started to consider ways to close gaps in its pedestrian and bicycle networks. Moreover, contemporary design and civic policy have evolved to embrace the dichotomies of everyday life constantly experienced in Naples, including: private auto use versus public transit, accessibility versus mobility, private versus public spaces, and day versus night use. Design criteria were required to rehabilitate this pluralistic area, with its modern economy based heavily on international tourism that 'never sleeps'.

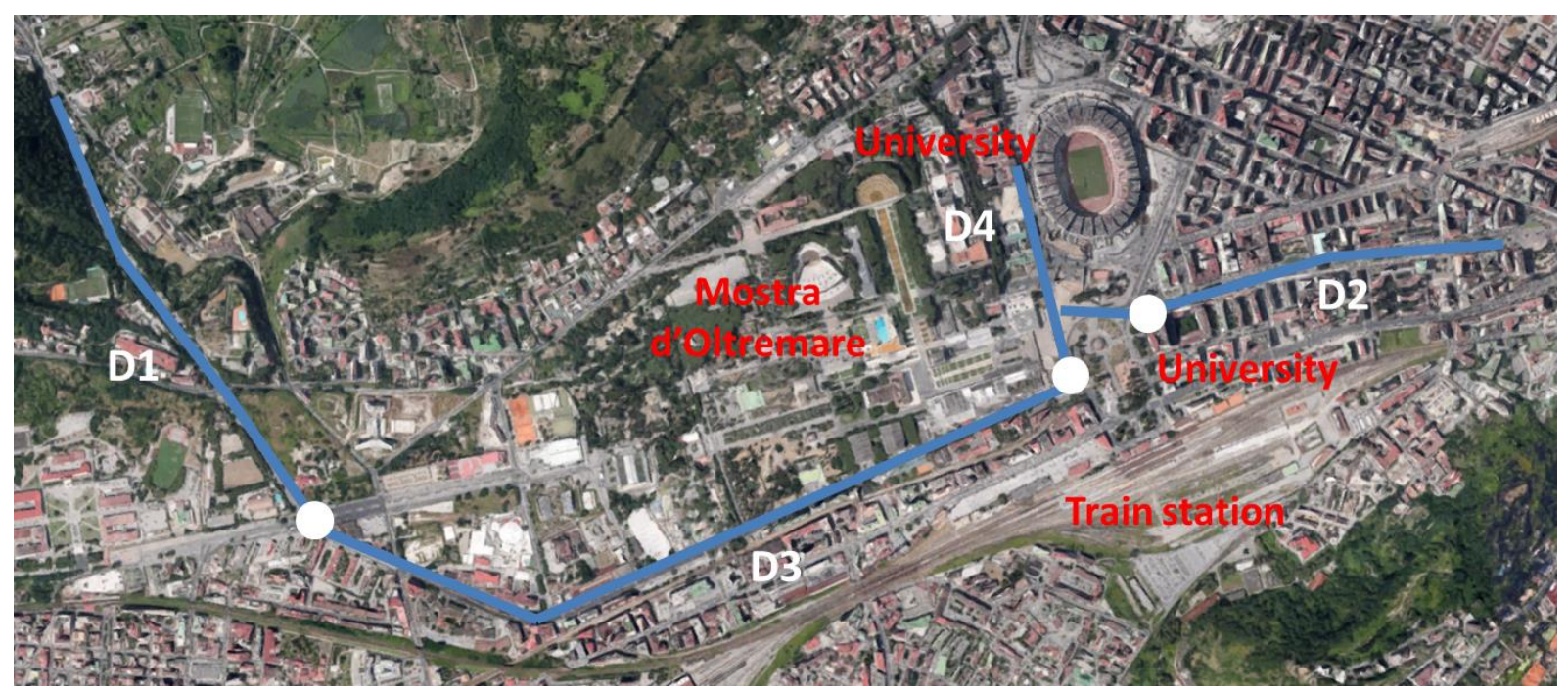

Figure 1. Study area.

The Mostra environmental and architectural rehabilitation was aimed at recovering its urban character in the context of its historical significance, while addressing its growing circulation, access, and aesthetics needs, including changes to the streetscape and networks. Specific problems that the project had to address related to:

- Urban streets with features of rural roads (D1 in Figure 1, Figures 2a and 3a);

- Layouts of urban spaces with poor consideration of environment, aesthetics, and liveability (D2 in Figure 1, Figures 4a and 5a);

- Inadequate and discontinuous pedestrian and bicycle paths (D3 in Figure 1, Figures 6a and 7a); and,

- Pedestrian and bicycle routes in the layout of roads for motorized vehicles (D4 in Figure 1, Figures 8a and 9a).

The safety issues of the existing network were assessed by safety inspections (criterion S1, see Table 1) and the project's crash potential and safety performance were evaluated by a road safety audit (criterion S2).

Practical application of the sustainable complete streets design criteria is presented with reference to four specific designs of the Mostra project which are aimed at solving the issues presented above. Table 2 synthesises the specific criteria applied in the case studies. 
Table 2. Sustainable complete streets design criteria.

\begin{tabular}{|c|c|c|c|c|c|}
\hline $\begin{array}{l}\text { General } \\
\text { criteria }\end{array}$ & $\begin{array}{l}\text { Specific } \\
\text { criteria }\end{array}$ & Design 1 & Design 2 & Design 3 & Design 4 \\
\hline \multirow[t]{3}{*}{ Aesthetics } & $\begin{array}{l}\text { A1 Enhancement of the urban } \\
\text { environment to recover historical urban } \\
\text { character and realize historical area } \\
\text { planning goals }\end{array}$ & $\checkmark$ & $\checkmark$ & & $\checkmark$ \\
\hline & $\begin{array}{l}\text { A2 Integration of materials, colours, } \\
\text { lighting, and treatment of green spaces }\end{array}$ & $\checkmark$ & $\checkmark$ & $\checkmark$ & $\checkmark$ \\
\hline & A3 Durable materials & $\checkmark$ & $\checkmark$ & $\checkmark$ & \\
\hline \multirow[t]{3}{*}{ Environment } & E1 Eco-design & $\checkmark$ & $\checkmark$ & $\checkmark$ & $\checkmark$ \\
\hline & E2 Planting and trees & $\checkmark$ & $\checkmark$ & $\checkmark$ & $\checkmark$ \\
\hline & $\begin{array}{l}\text { E3 Reduction of traffic-related air pollution } \\
\text { and noise }\end{array}$ & $\checkmark$ & $\checkmark$ & $\checkmark$ & $\checkmark$ \\
\hline Liveability & $\begin{array}{l}\text { L1 Usability, comfort and safety of the } \\
\text { public outdoor space system }\end{array}$ & & $\checkmark$ & $\checkmark$ & $\checkmark$ \\
\hline & $\begin{array}{l}\text { L2 Creation of a public space destination in } \\
\text { the urban landscape which affects } \\
\text { activities and social relations }\end{array}$ & & $\checkmark$ & & $\checkmark$ \\
\hline \multirow[t]{9}{*}{ Safety } & S1 Road safety inspections & $\checkmark$ & $\checkmark$ & $\checkmark$ & $\checkmark$ \\
\hline & S2 Road safety audits & $\checkmark$ & $\checkmark$ & $\checkmark$ & $\checkmark$ \\
\hline & S3 Fused Grid neighbourhood pattern & $\checkmark$ & $\checkmark$ & $\checkmark$ & $\checkmark$ \\
\hline & S4 Safe pedestrian routes and crosswalks & $\checkmark$ & $\checkmark$ & $\checkmark$ & $\checkmark$ \\
\hline & S5 Safe cycle routes and crossings & $\checkmark$ & $\checkmark$ & $\checkmark$ & $\checkmark$ \\
\hline & S6 Sight distance & & $\checkmark$ & $\checkmark$ & \\
\hline & S7 Transit and pedestrian accessibility & & $\checkmark$ & $\checkmark$ & \\
\hline & S8 Traffic control devices & $\checkmark$ & $\checkmark$ & & \\
\hline & S9 Lighting & $\checkmark$ & $\checkmark$ & $\checkmark$ & $\checkmark$ \\
\hline
\end{tabular}




\subsection{Design 1 - Urban Streets with Features of Rural Roads}

The rural character (Figures 2a and 3a) of some streets in Mostra have a significant impact on its liveability. They encourage high speeds, discourage pedestrian and bicycle traffic, and generally dampen human-scale activities. To recover the urban character and improve access and visibility to the entire Mostra area, the design principles built on an homogeneous choice of materials, colours, lighting and treatment of green, including (Figures $2 b$ and $2 b$ ):

- The steel median safety barrier was replaced with a blue colour concrete median barrier with rounded shape (criterion A1, see Table 1);

- Pedestrian crossings with white zebra stripes were embedded in a red colour surface with printed bituminous concrete appearing as brick pavers (criteria S3, S4 and S8);

- The uneven and potholed pavement was replaced with an even antiskid surface (criteria A1, A3, and E1);

- The carriageways without markings were marked with high performance cold hardened road markings delineating $3.50 \mathrm{~m}$ wide traffic lanes (criteria A3, S3, and S8);

- Both sides of the road had one-way separated bicycle lanes installed (criteria A2, E1, E2, E3, S3, S5, and S9), with these features:

- raised from the street and flush with the sidewalk,

- width equal to $1.50 \mathrm{~m}$,

- red colour bituminous concrete surface,

- $0.70 \mathrm{~m}$ buffer from the street via basalt curb and concrete square slabs,

- $1.00 \mathrm{~m}$ buffer from the sidewalks made by concrete square slabs, trees with regular spacing, and lighting poles with LED sources;

- Continuous and accessible sidewalks $1.50 \mathrm{~m}$ wide were installed (criteria S3 and S5); and,

- The existing, obstructive advertising signs were removed from sidewalks (criteria A1 and A2). 


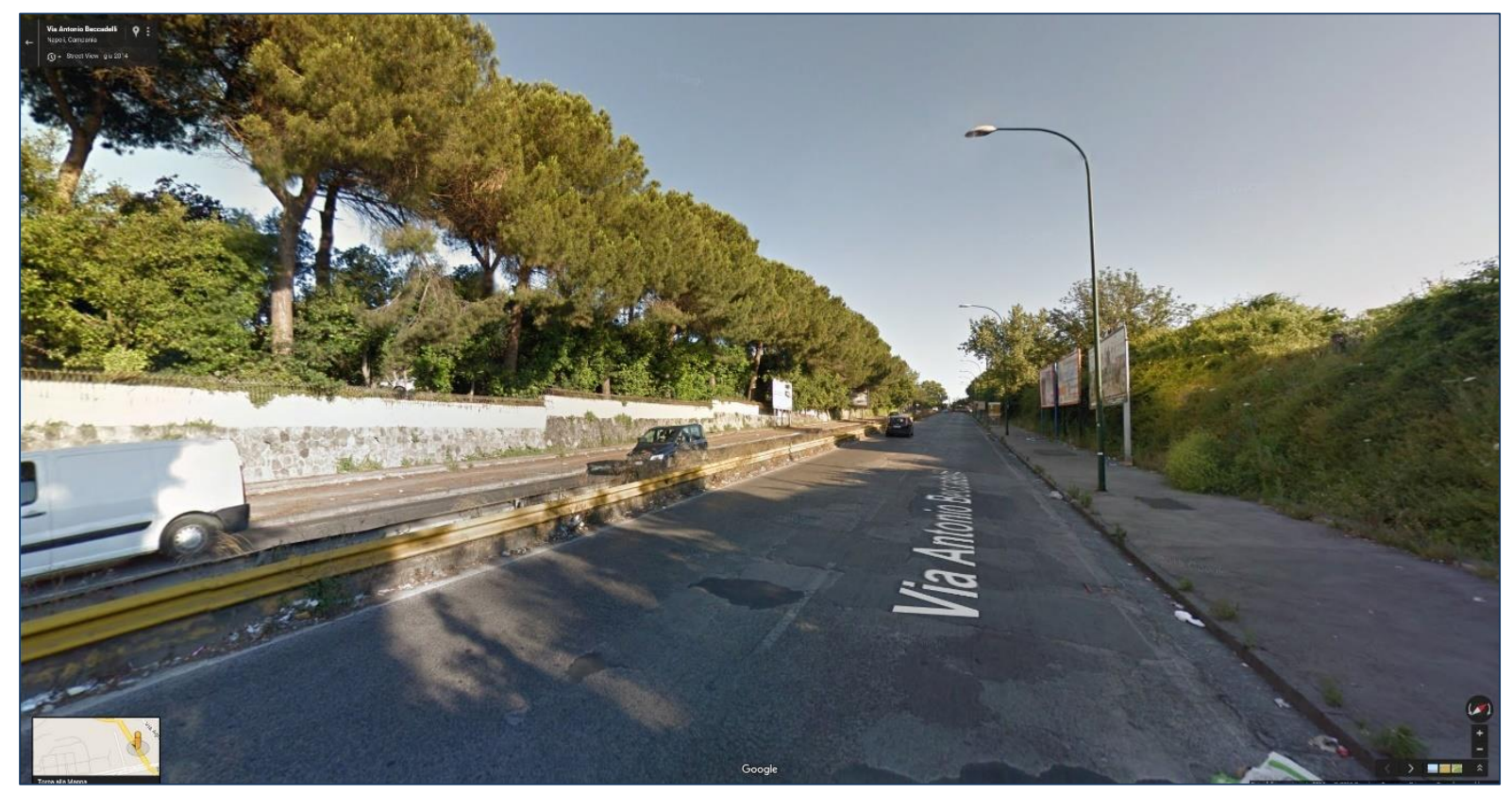

a) Existing scenario

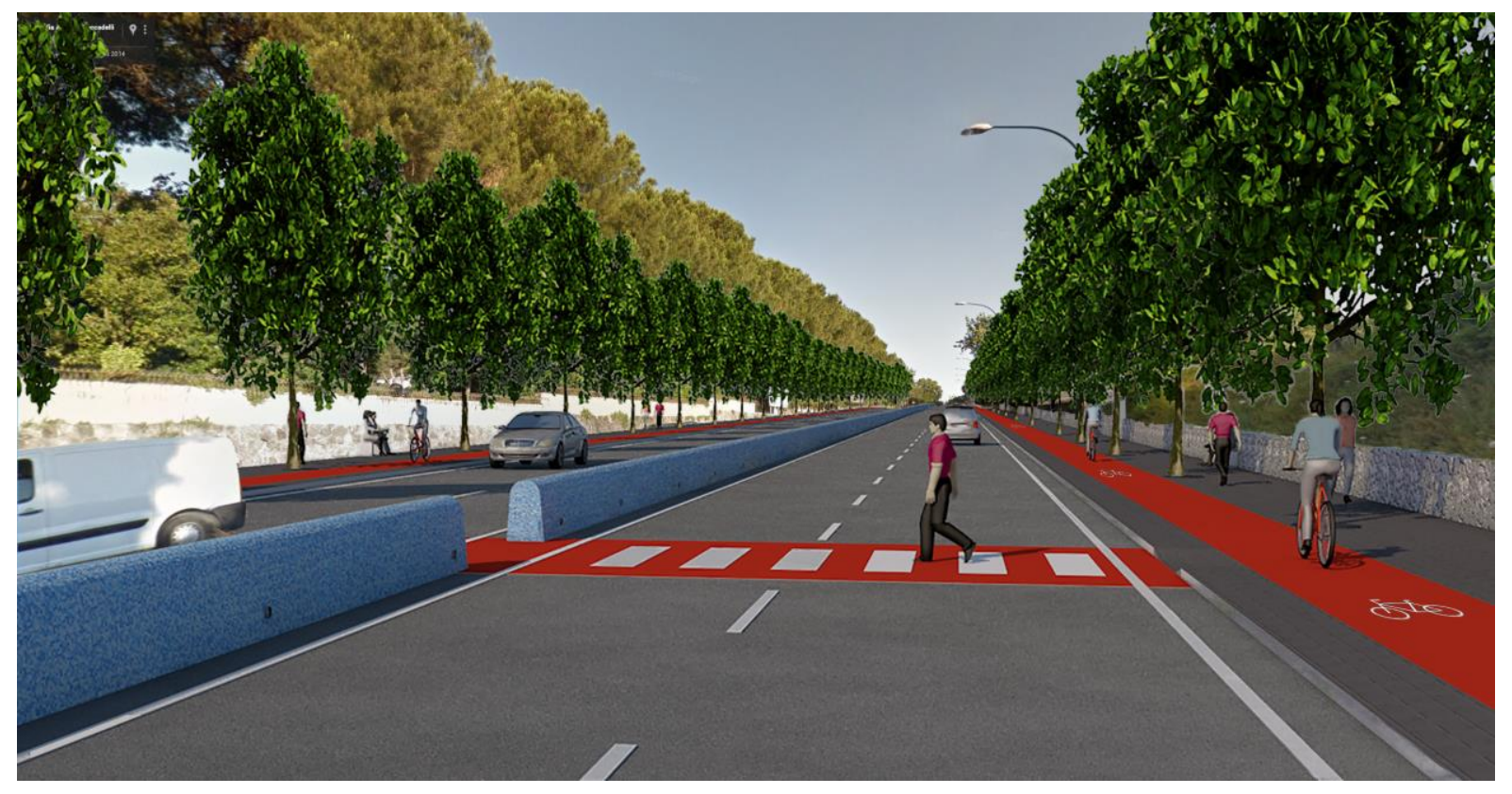

b) Design scenario

Figure 2. Urban street with features of a rural road: example of design improvement. 


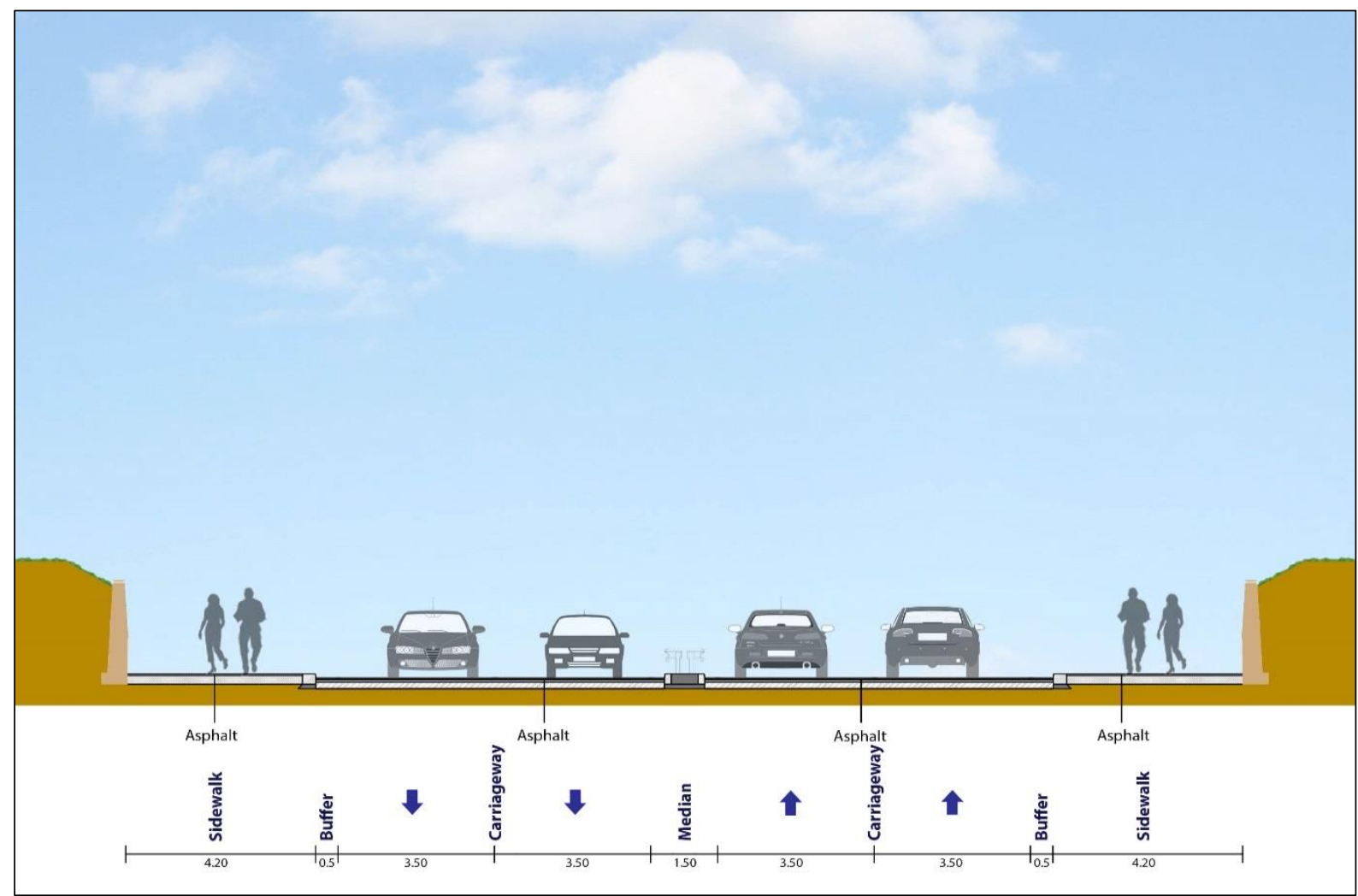

a) Existing scenario

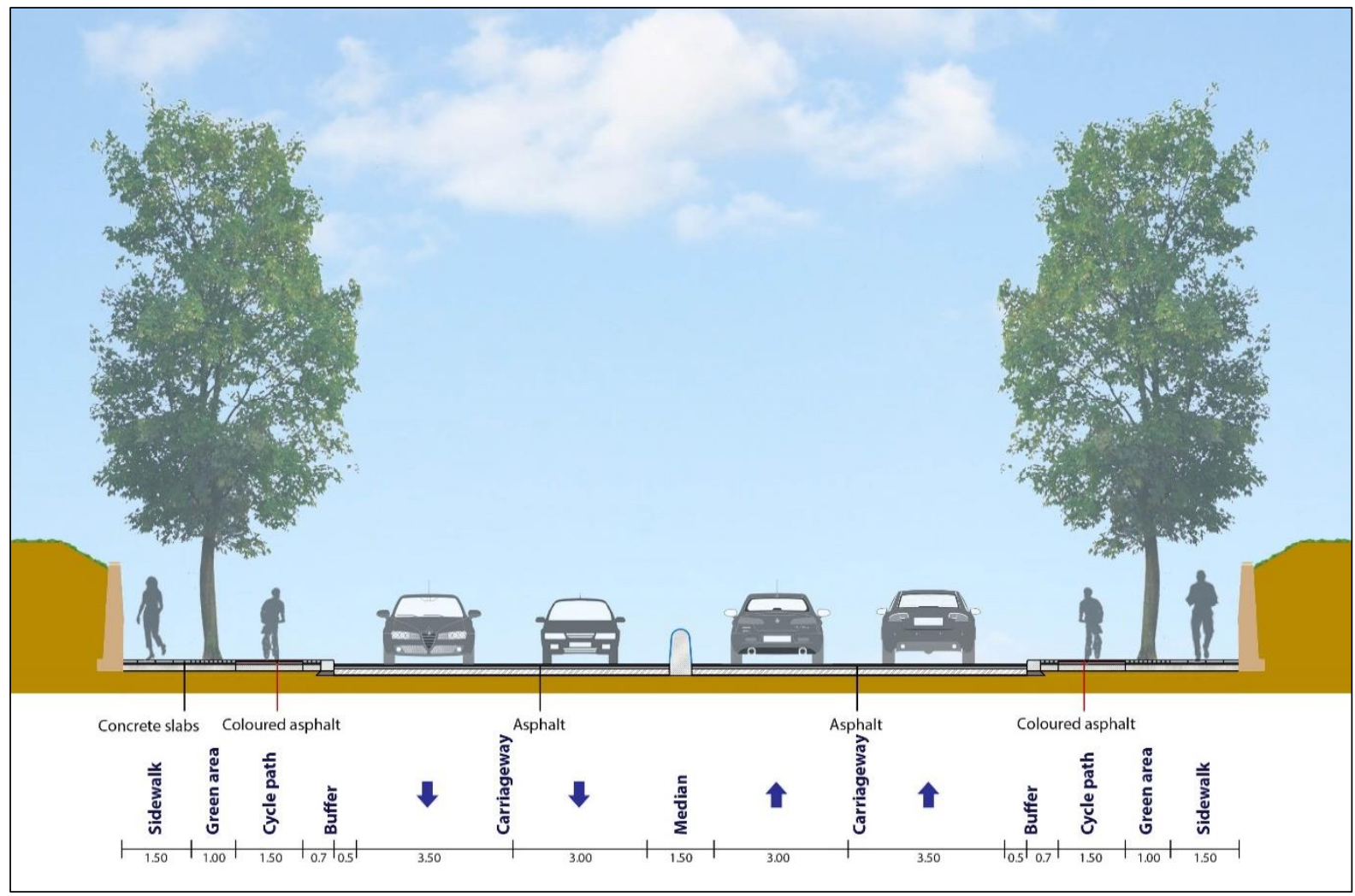

b) Design scenario

Figure 3. Urban street with features of a rural road: existing (a) and design (b) cross section. 


\subsection{Design 2 - Inadequate Layout}

Viale di Augusto, which is the most important street in the Mostra area, is characterised by a layout with poor consideration of environment, aesthetics, and liveability (Figure 3a and 4a). Its wide median is not used by pedestrians or cyclists, and, its aesthetic quality is very poor. Moreover, historical palms had died, and car parking was allowed in its median, creating dangerous conflicts between through traffic and people crossing the street to reach their parked vehicles. At some point in the past, a separate two-way bicycle lane had been installed in one carriageway creating an abnormal-width carriageway of two $2.25 \mathrm{~m}$ lanes (plus a $0.50 \mathrm{~m}$ shoulder). Most important, the bicycle lane had been used more by pedestrians and parents with strollers due to inadequate alternatives and obstructions in historical sidewalk areas (e.g., parked cars, scooters, and street furniture). To solve these issues, a combination of measures was designed (Figures $3 \mathrm{~b}$ and $4 \mathrm{~b}$ ), including:

- The median was completely redesigned with new trees (indigenous, hardy species) and pedestrian and bicycle paths (criteria A1, A2, E2, E3, S3, S4, and S5);

- In the median, a continuous pedestrian route was created, with central plazas and benches at regular intervals (criteria L1 and L2);

- In the median, one-way separated bicycle lanes were introduced, flush with the sidewalk, $1.50 \mathrm{~m}$ wide, with red colour bituminous concrete surface, and $0.70 \mathrm{~m}$ buffer from the street (criterion S5);

- Parking in the median was removed (criterion S3);

- The former counter-flow bicycle lane was removed (criterion L1);

- Parallel parking was introduced in nearside with a different surface, i.e., red colour surface with printed bituminous concrete appearing as brick pavers (criteria A3 and E1);

- Bulb-outs were introduced in all the pedestrian crossings (criteria S4 and S6);

- Lighting poles with LED sources were employed (criteria L2 and S9);

- Antiskid surfaces were added (criteria A3 and E1);

- High performance cold hardening road markings was specified, delineating $3.50 \mathrm{~m}$ wide outer lanes (where bus are expected) and $3.00 \mathrm{~m}$ wide inner lanes (criteria A3, S3, and S8); and,

- On each side of the Viale, new continuous and accessible sidewalks with concrete square slabs were installed (criteria L1 and S7). 


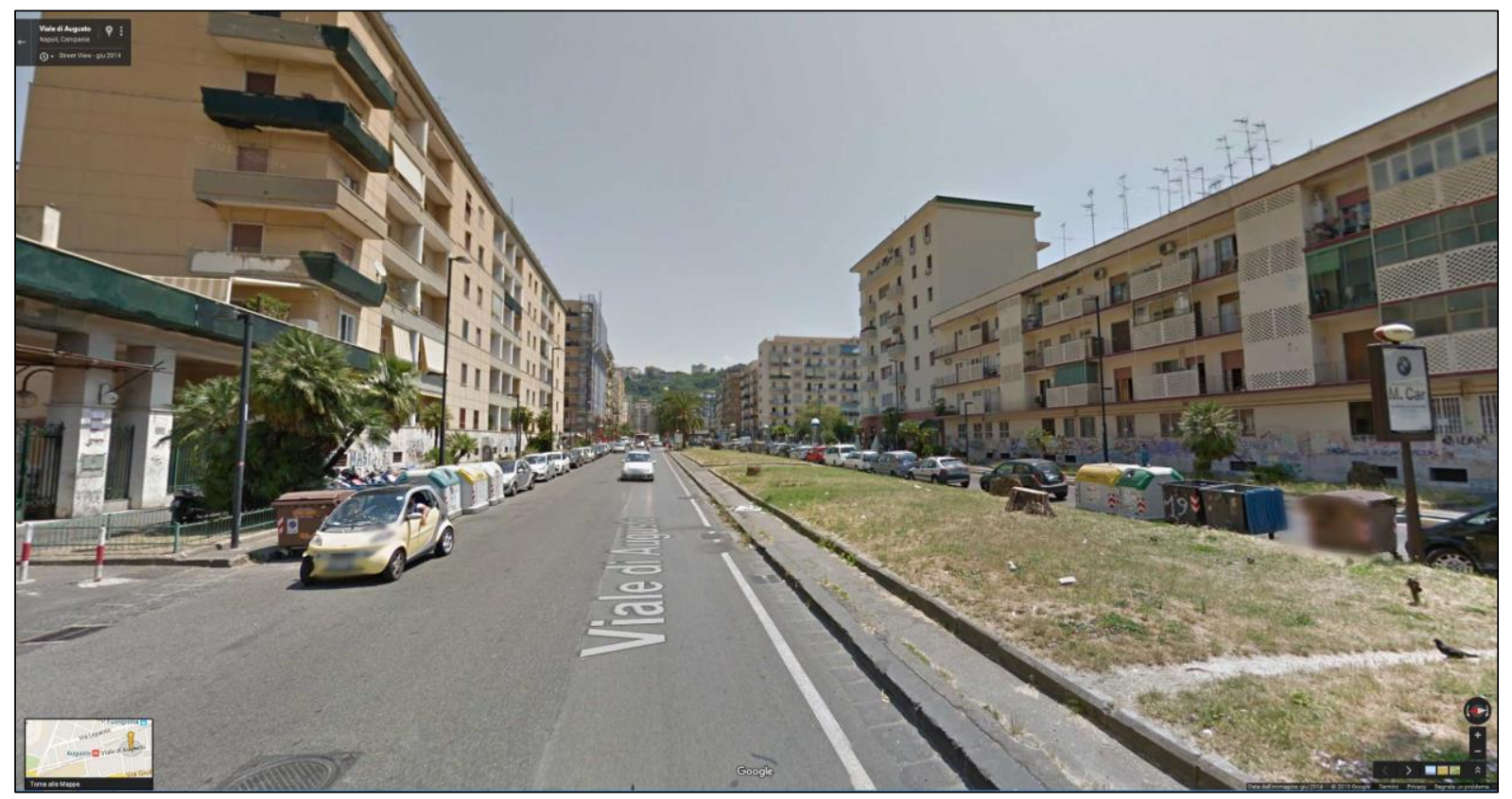

a) Existing scenario

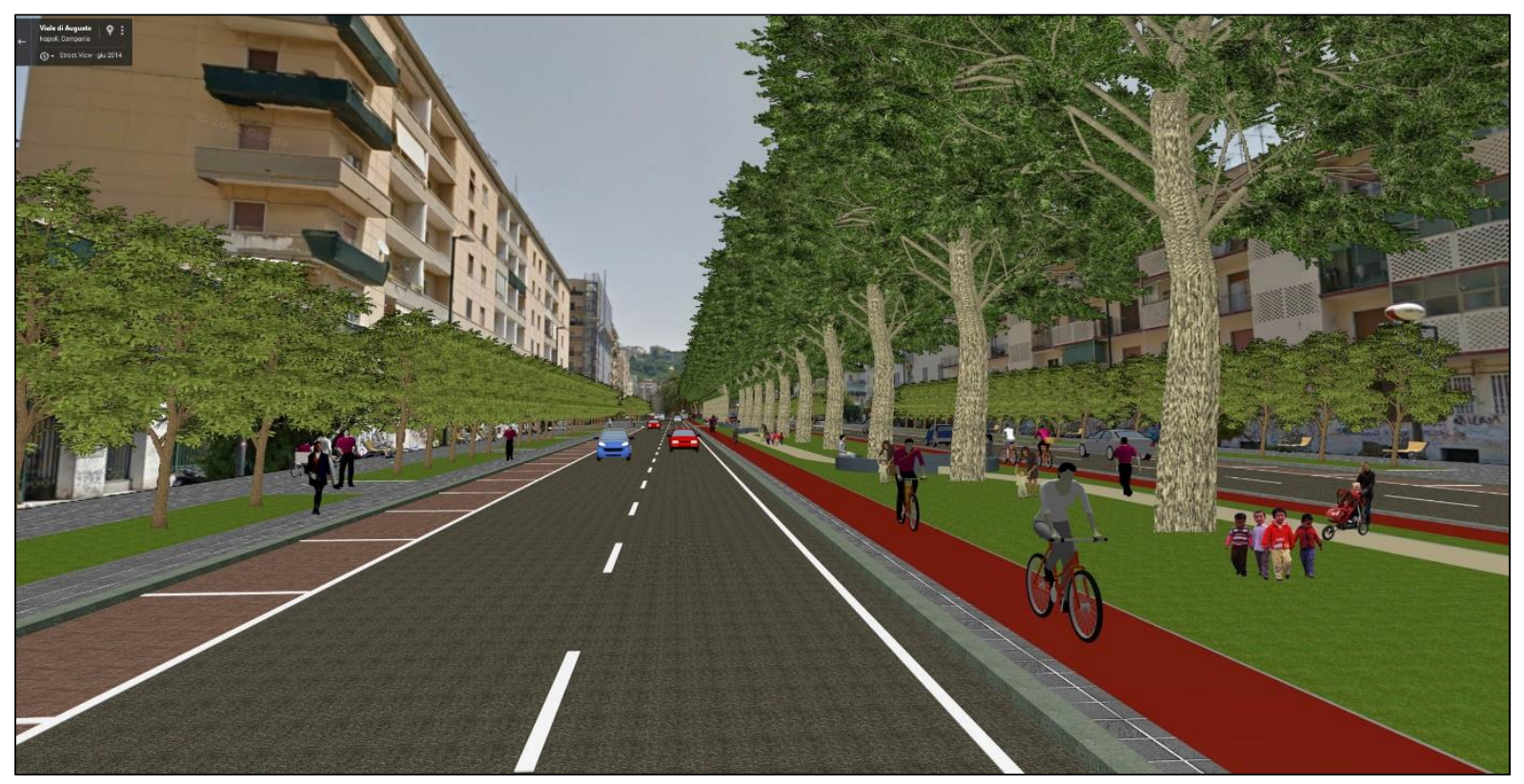

b) Design scenario

Figure 4. Layout of urban space with poor consideration of environment, aesthetics, and liveability: example of design improvement. 


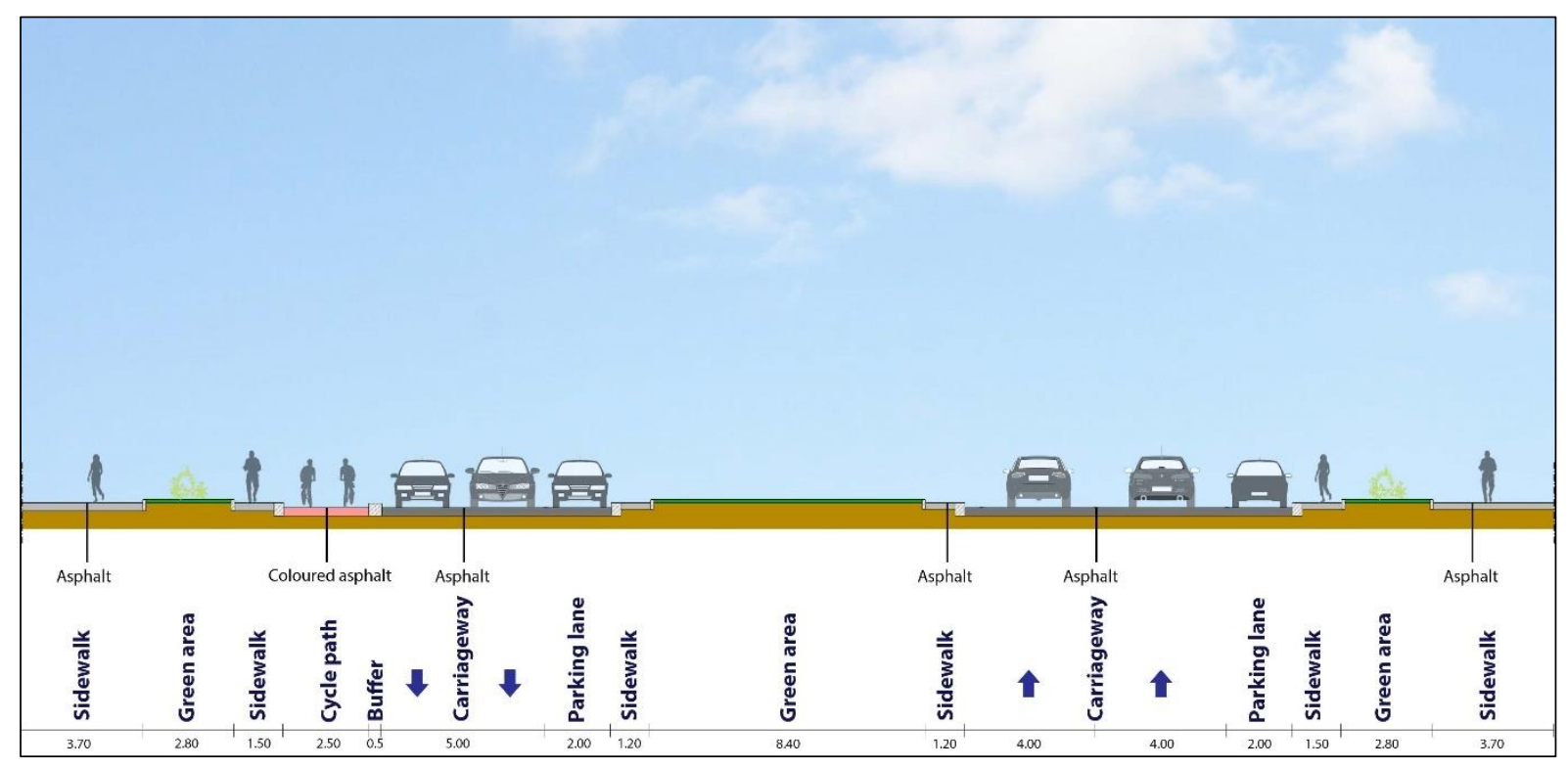

a) Existing scenario

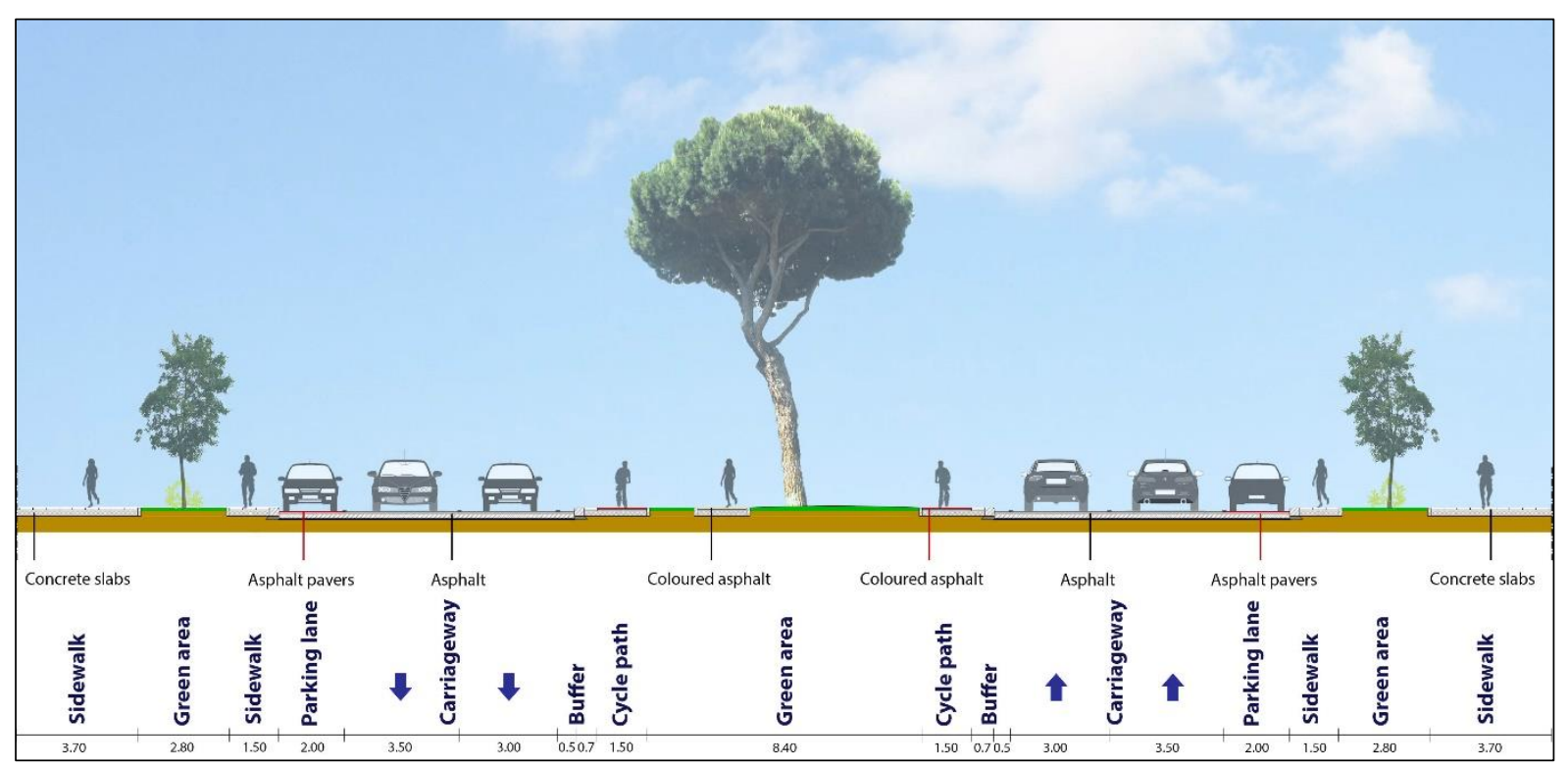

b) Design scenario

Figure 5. Layout of urban space with poor consideration of environment, aesthetics, and liveability: existing (a) and design (b) cross section. 


\subsection{Design 3 - Inadequate Pedestrian and Bicycle Paths}

On another part of the road network, Viale Kennedy, a two-way bicycle lane had been installed over existing sidewalks, which imperilled pedestrians, and, many parts of the Viale had no street trees (Figures 6a and 7a). To solve these issues, the design included (Figures 6b and 7b):

- Replacement of the existing two-way bicycle lane with one-way separated bicycle lanes on both sides (criteria L1, S3, S5) that were flush with the sidewalk, including a $1.50 \mathrm{~m}$ wide, red coloured, bituminous concrete surface, separated by a $1.30 \mathrm{~m}$ basalt curb buffer, street trees, and LED street lights (criteria A2, E1, E2, E3, S3, S5, and S9);

- Continuous and accessible pedestrian paths $2.00 \mathrm{~m}$ wide (criteria S4 and S7);

- Bulb-outs in all the pedestrian crossings (criteria S4 and S6);

- $\quad$ Lane widths reduced from $4.00 \mathrm{~m}$ to $3.50 \mathrm{~m}$ (criterion S3);

- $\quad$ Antiskid surfaces (criteria A3 and E1); and

- High performance cold hardening road markings (criteria A3, S3, and S8). 


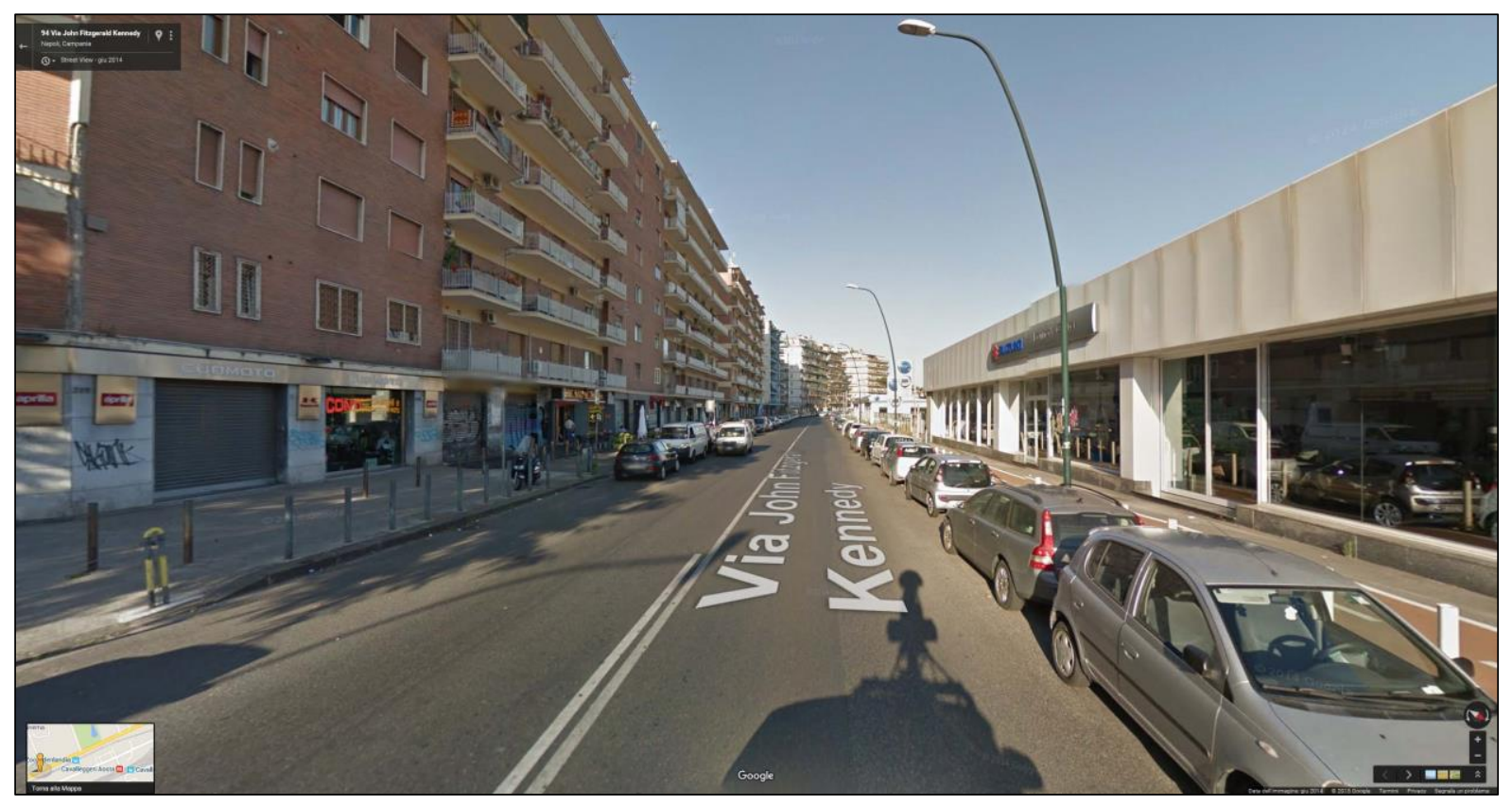

a) Existing scenario

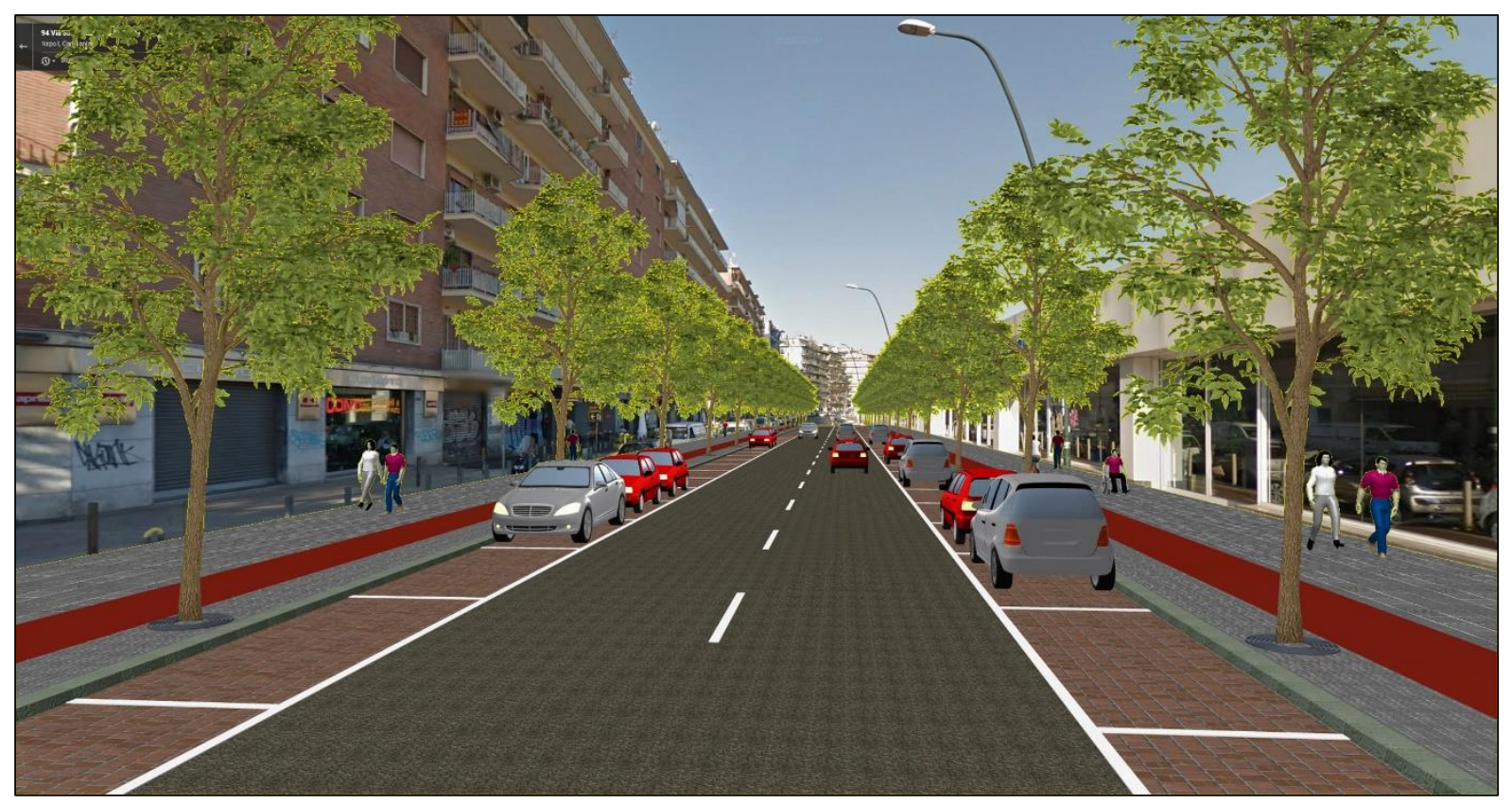

b) Design scenario

Figure 6. Inadequate and discontinuous pedestrian and bicycle paths: example of design improvement. 


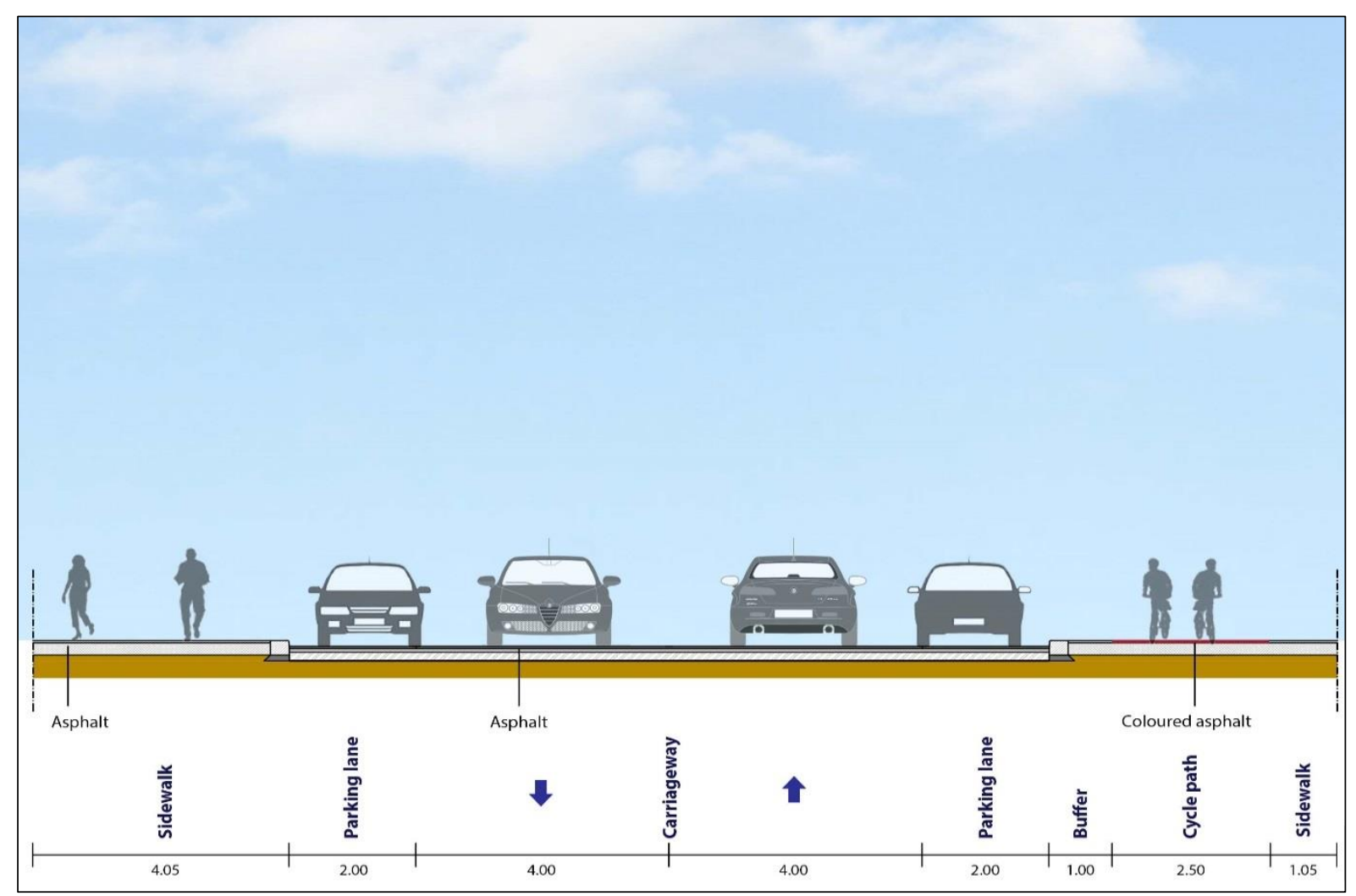

a) Existing scenario

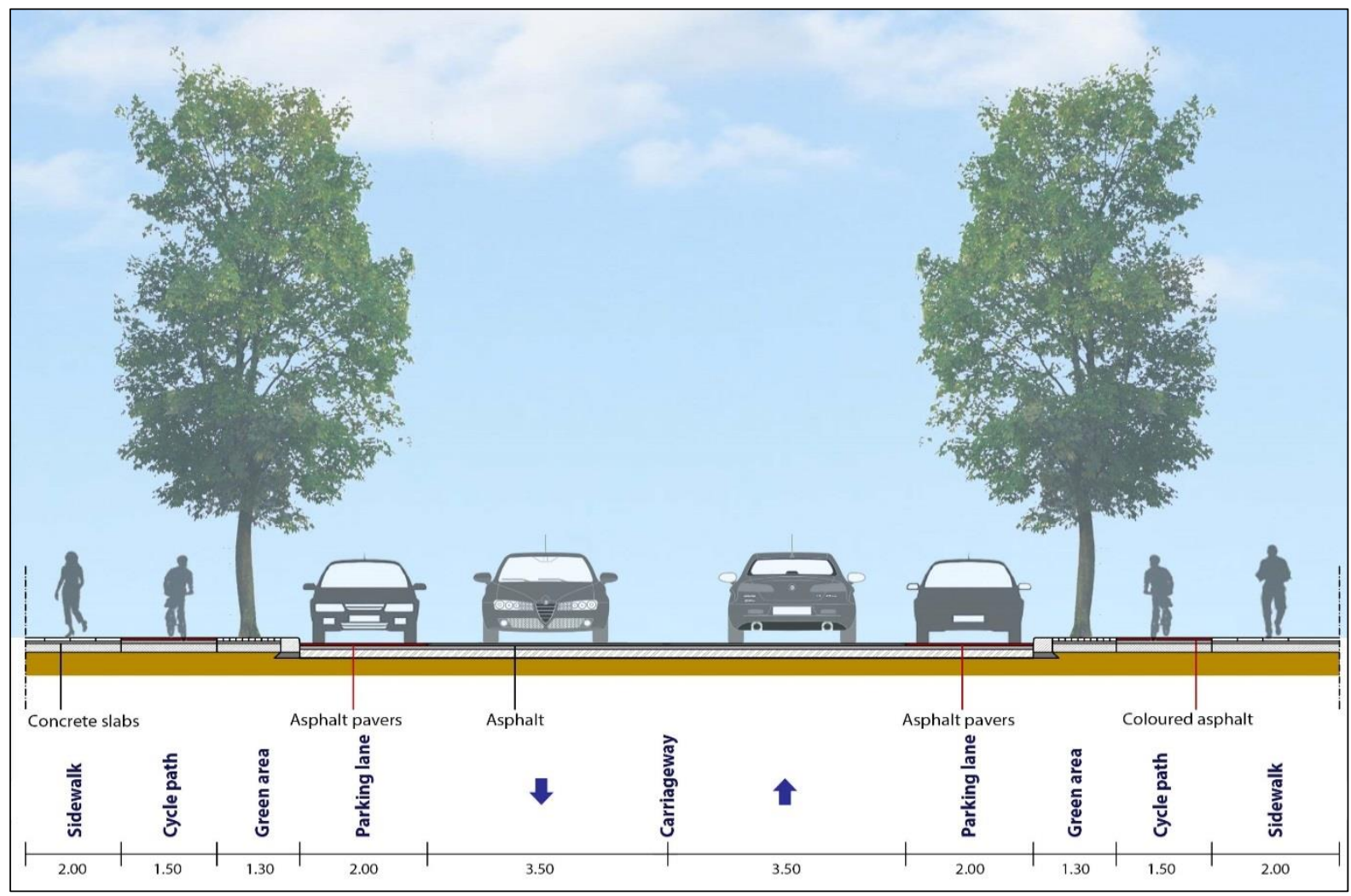

b) Design scenario

Figure 7. Inadequate and discontinuous pedestrian and bicycle paths: existing (a) and design (b) cross section. 


\subsection{Design 4-Conflicts between Pedestrians, Cyclists, and Cars}

In Via Claudio (Figures 8a and 9a) the design needed to address high pedestrian and bicycle flows, as the street connects the north and the south campuses of the School of Engineering at the University of Naples. It also connects the north campus with a bus stop and the railway station. Because of its high use by vulnerable users, this street had been designated as a shared pedestrian and bicycle route closed to car traffic. However, lack of police and physical enforcement (i.e. no selfenforcing physical barriers) had allowed the Via to historically be used as a shortcutting route for auto traffic, despite having no separated sidewalks nor bicycle lanes, which caused continuing VRU/auto conflicts (Figure 8a). A combination of countermeasures was designed, including (Figures $8 b$ and $9 b)$ :

- Removal of the concrete pavement (criteria A1 and A2);

- Installation of green strips on both sides with grass, trees, benches, and lighting poles with LED sources (criteria E1, E2, E3, L1, L2, and S9);

- Installation of a two-way bicycle lane, flush with the sidewalk, $3.00 \mathrm{~m}$ wide, with red colour bituminous concrete surface (criteria L1, L2, S3, and S5);

- Installation of a $1.00 \mathrm{~m}$ wide buffer between the bicycle lane and sidewalk, using concrete square slabs (criteria S3, S4, and S5);

- Installation of a $2.00 \mathrm{~m}$ wide coloured sidewalk (criteria S3 and S4); and,

- Installation of 'gateway' architectural features at its ends (criteria A1, L1, and L2). 


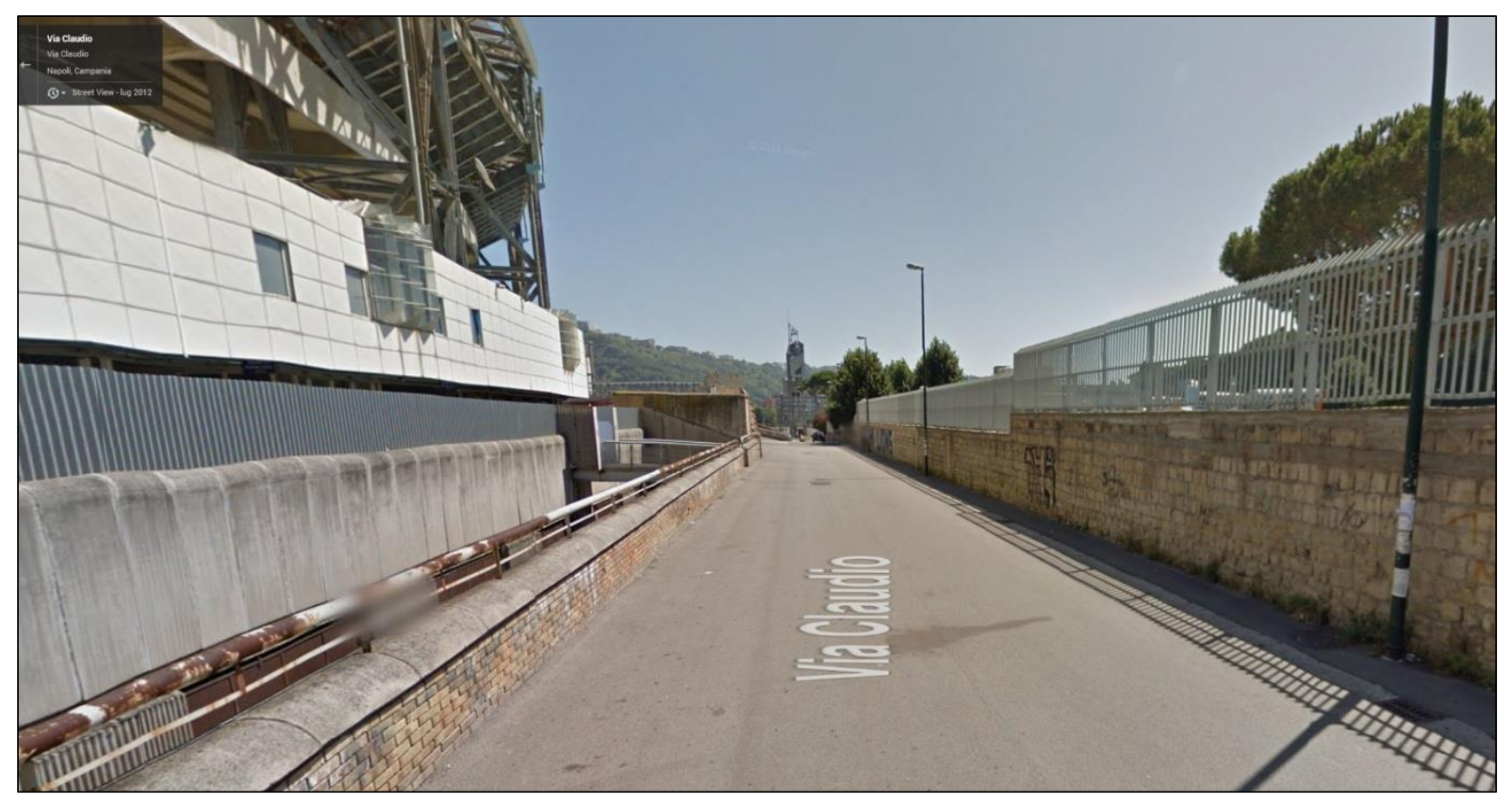

a) Existing scenario

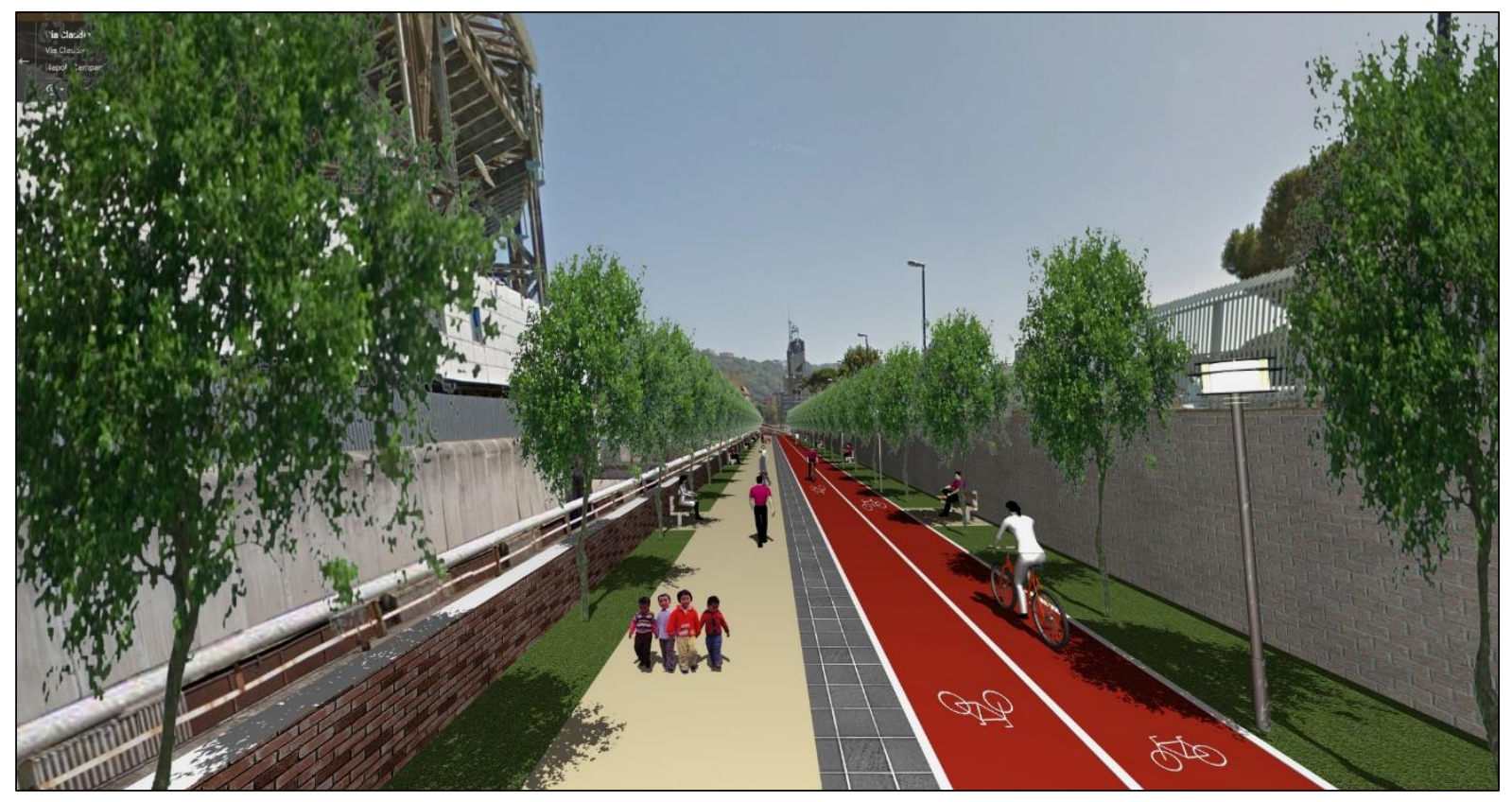

b) Design scenario

Figure 8. Pedestrian and bicycle routes in the layout of roads for motorized vehicles: example of design improvement. 


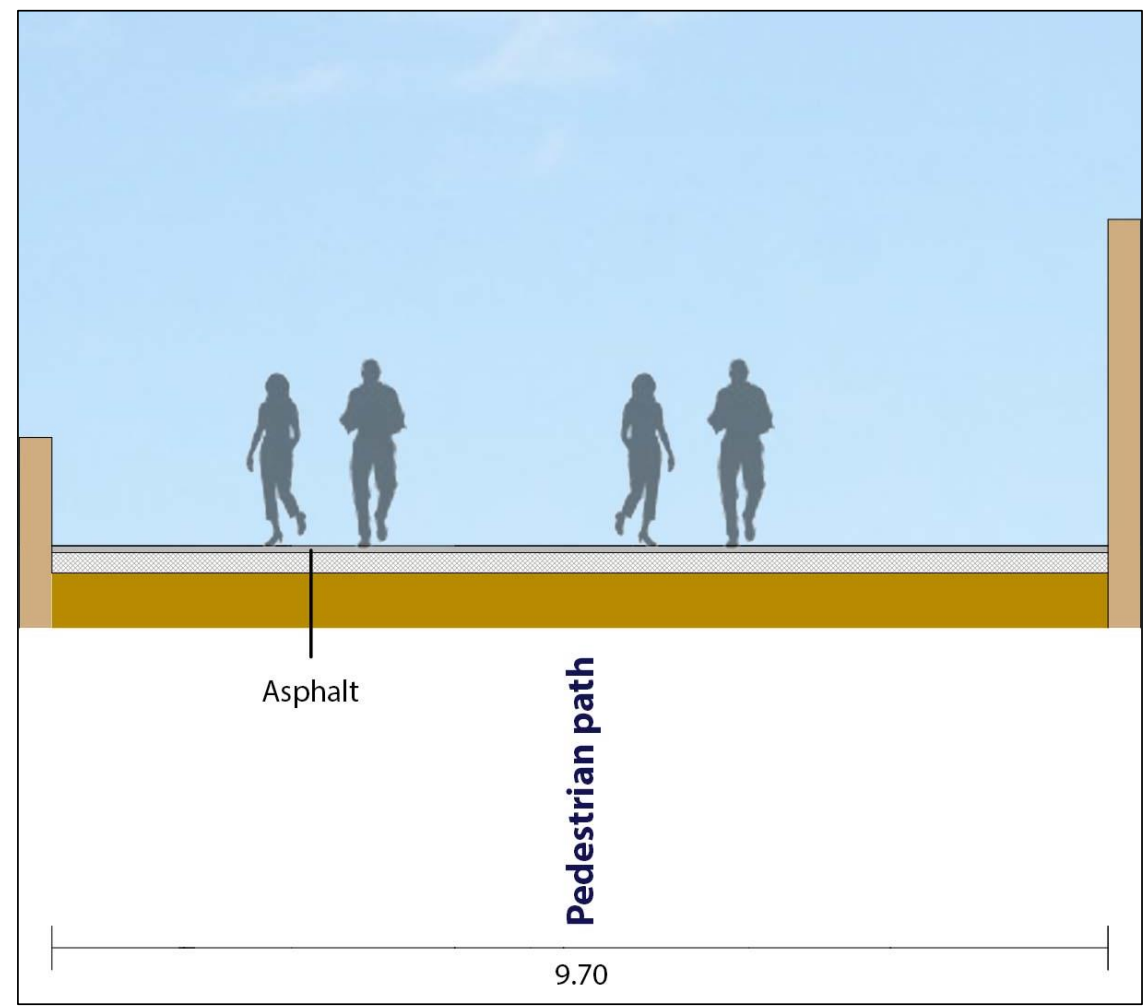

a) Existing scenario

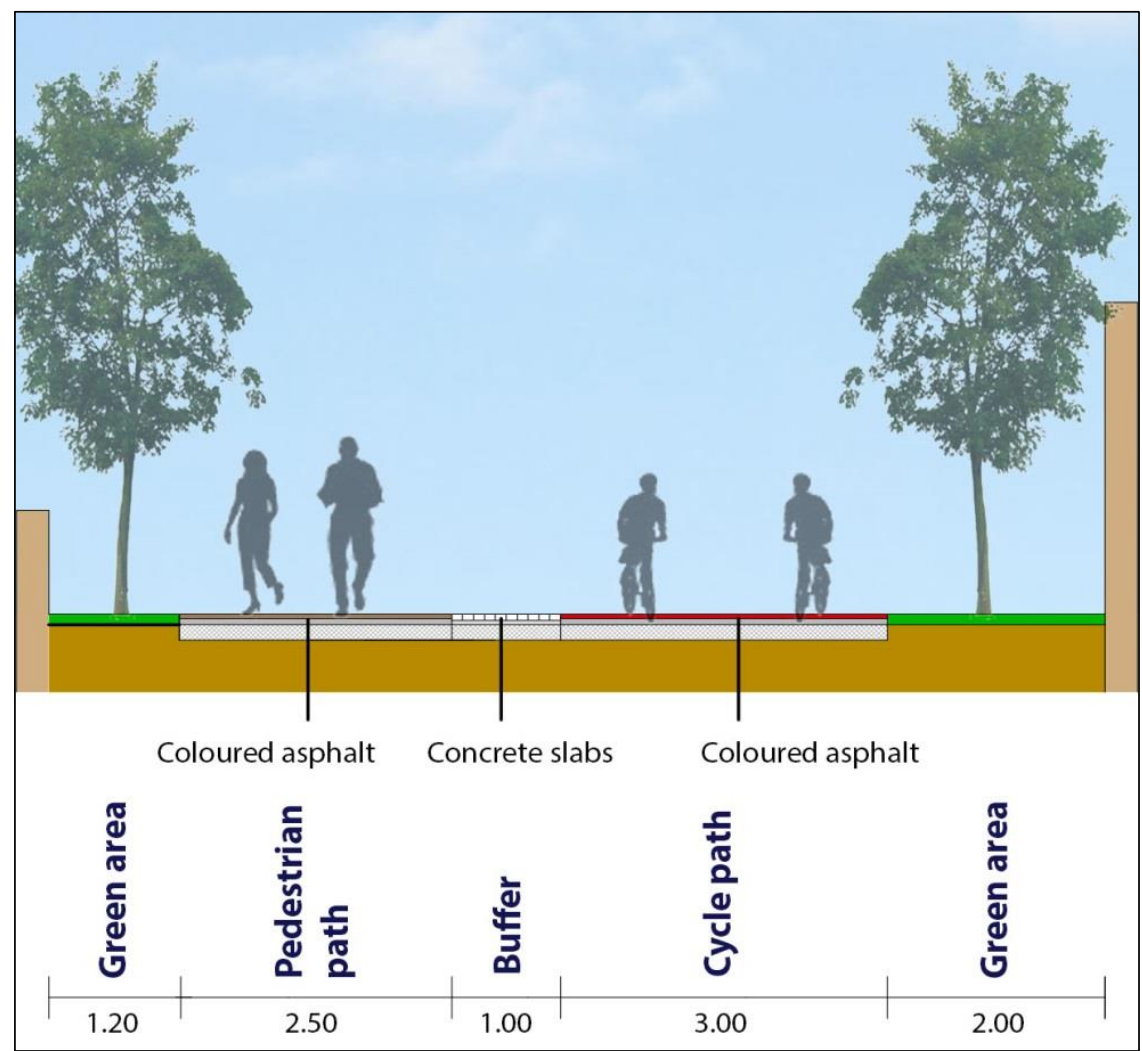

b) Design scenario

Figure 9. Pedestrian and bicycle routes in the layout of roads for motorized vehicles: existing (a) and design (b) cross section. 


\section{Discussion and conclusions}

Streets are important public spaces for many aspects of daily life and have significant effects on the liveability of the city, but road designs and functions have evolved from a local context focus to a broader connecting focus such that they no longer give consideration to these local contextual needs. This paper has proposed and discussed sustainability-oriented, eco-design urban street design criteria that are meant to complement and build on existing complete streets design criteria. Specifically, the term 'sustainably complete streets' design criteria has been coined to denote the addition of socio-environmental design criteria related to aesthetics, environment, liveability, and safety. The main goal of these proposed sustainable complete streets design criteria is to provide a street network adapted to contemporary requirements for community sustainability, quality of life, and vulnerable road user safety, while providing for traditional urban mobility, historic context, and efficiency. If a system approach is taken as advocated, the benefits will include: reduced motorized traffic, reduced energy consumption, reduced traffic noise, reduced air pollution, and increased pedestrian, bicycle, and public transport traffic and safety. At the same time criteria are included to improve the aesthetic and liveability quality of public and/or green space. This is done through urban design solutions for structured and consistent thematic areas aimed at a unified picture of homogeneous urban zones.

Proposed criteria look at environmental and architectural restoration to recover urban character in respect of the historical evolution and urban planning of an area. Using a systematic and team-based approach, the design solution can create a road environment that serves both functional and local needs. Local context and architectural design principles support a homogeneous, unified approach as regards the choice of materials, colours, lighting, and treatment of the green spaces. An eco-design approach is proposed, and special emphasis is given to planting and tree species and to the implementation and increase of the permeable surfaces in order to reduce the heat island effect, and to absorb air pollution caused by vehicular traffic.

The case study of the urban rehabilitation of the "Mostra d'Oltremare" area and of its cultural and architectural assets in Naples, Italy, highlights the practical application of these proposed criteria and the possibility of using these criteria in other urban contexts. The case study shows both how each specific criteria were applied and how the concept of sustainable complete streets can contribute to the urban aesthetics, environment, liveability, and safety.

Author Contributions: Conceptualization, Salvatore Chiaradonna, Alessandro Claudi de Saint Mihiel, Gord Lovegrove, Alfonso Montella, and Pietro Nunziante; methodology, Salvatore Chiaradonna, Alessandro Claudi de Saint Mihiel, Gord Lovegrove, Alfonso Montella, and Pietro Nunziante; validation, Salvatore Chiaradonna and Alfonso Montella; investigation, Salvatore Chiaradonna, Alessandro Claudi de Saint Mihiel, Alfonso Montella, and Pietro Nunziante; writing - original draft preparation, Salvatore Chiaradonna, Alessandro Claudi de Saint Mihiel, Alfonso Montella, and Pietro Nunziante; writing - review and editing, Salvatore Chiaradonna, Alessandro Claudi de Saint Mihiel, Alfonso Montella, and Pietro Nunziante; supervision, Alfonso Montella. All authors have read and agreed to the published version of the manuscript.

Funding: This research received no external funding.

Acknowledgments: The authors acknowledge Professor Mario Calabrese, councilor for public works of the City of Naples, for his technical support.

Conflicts of Interest: The authors declare no conflict of interest.

\section{References}

1. Transportation Research Board, 2006. International Perspectives of Urban Street Design. Transportation Research Circular E-C097. Retrieved at http://onlinepubs.trb.org/onlinepubs/circulars/ec097.pdf.

2. Gregg, K.; Hess, P. Complete streets at the municipal level: A review of American municipal Complete Street Policy. Int. J. Sustain. Transp. 2019, 13(6), pp. 407-418, https://doi.org/10.1080/15568318.2018.1476995. 
3. Institute of Transportation Engineering. Designing Walkable Urban Thoroughfares: A Context Sensitive Approach. Publication No. RP-036A, Washington, D.C., 2010. Retrieved at http://library.ite.org/pub/e1cff43c-2354-d714-51d9-d82b39d4dbad.

4. Institute of Transportation Engineering. Integration of Safety in the Project Development Process and Beyond: A Context Sensitive Approach. Publication No. IR-140, Washington, D.C., 2015. Retrieved at http://library.ite.org/pub/e4edb88b-bafd-b6c9-6a19-22e98fedc8a9.

5. McCann, B. Completing our streets: the transition to safe and inclusive transportation networks. Island press, Washington, D.C., 2013.

6. National Association of City Transportation Officials. Urban Street Design Guide. New York, NY, 2013. Retrieved at https://nacto.org/publication/urban-street-design-guide/.

7. National Complete Streets Coalition, 2015. Introduction to Complete Streets. Retrieved at https://smartgrowthamerica.org/resources/introduction-to-complete-streets/.

8. Schlossberg, M.; Rowell, J.; Amos, D.; Sanford, K. Rethinking Streets: An Evidence-Based Guide to 25 Complete Street Transformations. Sustainable Cities Initiative, University of Oregon, Oregon, 2013.

9. Department for Transport. Manual for Streets. Thomas Telford Publishing, London, 2007. Retrieved at www.gov.uk/government/uploads/system/uploads/attachment data/file/341513/pdfmanforstreets.pdf.

10. Wegman, F.; Aarts, L. Advancing Sustainable Safety: National Road Safety Outlook for 2005-2020. SWOV Institute for Road Safety Research, Leidschendam, The Netherlands, 2006. Retrieved at www.swov.nl/sites/default/files/publicaties/rapport/dmdv/advancing_sustainable safety.pdf.

11. Manzini, E. New design knowledge. Des. Stud. 2009, 30(1), pp. 4-12, https://doi.org/10.1016/j.destud.2008.10.001.

12. Vezzoli, C.; Manzini, E. Design for Environmental Sustainability. Springer-Verlag, London, 2008.

13. Verheijen, M., 2016. Functional Ambiance. De Urbanisten. Retrieved at www.urbanisten.nl/pdf/Functional\%20Ambiance\%20-\%20artikel\%20Huig.pdf.

14. United Nations, 1987. Report of the World Commission on Environment and Development: Our Common Future. Retrieved at http://www.un-documents.net/our-common-future.pdf.

15. Grammenos, F.; Lovegrove, G. Remaking the City Street Grid - A Model for Urban and Suburban Development. McFarland Publishers, Jefferson, NC, 2015.

16. United Nations, 2010. Global Plan for the Decade of Action for Road Safety 2011-2020. Retrieved at www.who.int/roadsafety/decade of action/plan/english.pdf.

17. World Health Organization. Global Status Report on Road Safety 2018. Geneva, Switzerland, 2018.

18. European Commission, Directorate-General for Mobility and Transport. Interim evaluation of the Policy orientations on road safety 2011-2020. Brussels, Belgium, 2015.

19. Montella, A.; Marzano, V.; Mauriello, F.; Vitillo, R.; Fasanelli, R.; Pernetti, M.; Galante, F. Development of macro-level safety performance functions in the city of Naples. Sustainability 2019, 11(7), 1871, https://doi.org/10.3390/su11071871.

20. Montella, A.; de Oña, R.; Mauriello, F.; Rella Riccardi, M.; Silvestro, G. A data mining approach to investigate patterns of powered two-wheeler crashes in Spain. Accid. Anal. Prev. 2020, 134, 105251, https://doi.org/10.1016/j.aap.2019.07.027.

21. Austroads. Guide to Road Safety Part 6: Managing Road Safety Audits. Austroads Publication AGRS06/19, Sydney, New South Wales, 2019.

22. Cafiso, S.; La Cava, G.; Montella, A. Safety index for evaluation of two-lane rural highways. Transp. Res. Rec. 2007, 2019, pp. 136-145, https://doi.org/10.3141/2019-17.

23. Cafiso, S.; La Cava, G.; Montella, A. Safety Inspections as a Supporting Tool for Safety Management of Low-Volume Roads. Transp. Res. Rec. 2011, 2203, pp. 116-125, https://doi.org/10.3141/2203-15.

24. FHWA. A Systemic Approach to Safety: Using Risk to Drive Action. Report FHWA SA-15-054, 2016. Reteruved at https://safety.fhwa.dot.gov/systemic/fhwasa15054/apprch.pdf.

25. Montella, A. Safety reviews of existing roads: quantitative safety assessment methodology. Transp. Res. Rec. 2005, 1922, pp. 62-72, https://doi.org/10.3141/1922-09.

26. Montella, A. Roundabout in-service safety reviews: safety assessment procedure. Transp. Res. Rec. 2007, 2019, pp. 40-50, https://doi.org/10.3141/2019-06.

27. Montella, A., Mauriello, F., 2012. Procedure for ranking unsignalized rural intersections for safety improvement. Transp. Res. Rec. 2012, 2318, pp. 75-82. https://doi.org/10.3141/2318-09. 
28. Montella, A.; Guida, C.; Mosca, J.; Lee, J.; Abdel-Aty, M. Systemic approach to improve safety of urban unsignalized intersections: Development and validation of a Safety Index. Accid. Anal. Prev. 2020, 141, 105523, https://doi.org/10.1016/j.aap.2020.105523.

29. Thomas, L.; Sandt, L.; Zegeer, C.; Kumfer, W.; Lang, K.; Lan, B.; Horowitz, Z.; Butsick, A.; Toole, J.; Schneider, R. Systemic Pedestrian Safety Analysis. NCHRP Research Report 893, 2018. Retrieved at https://www.nap.edu/download/25255.

30. American Association of State Highway and Transportation Officials. Highway Safety Manual, First Edition. Washington, D.C., 2010.

31. Elvik, R. Comparative analysis of techniques for identifying hazardous road locations. Transp. Res. Rec. 2008, 2083, pp. 72-75, https://doi.org/10.3141/2083-08.

32. European Parliament. Directive 2008/96/EC on Road Infrastructure Safety Management. Brussels, Belgium, 2008.

33. European Parliament. Directive (EU) 2019/1936 of the European Parliament and of the Council of 23 October 2019 amending Directive 2008/96/EC on road infrastructure safety management. Brussels, Belgium, 2019.

34. Hauer, E.; Allery, B.K.; Kononov, J.; Griffith, M.S. How best to rank sites with promise. Transp. Res. Rec. 2004, 1897, pp. 48-54, https://doi.org/10.3141/1897-07.

35. Montella, A. A comparative analysis of hotspot identification methods. Accid. Anal. Prev. 2010, 42(2), pp. 571-581, https://doi.org/10.1016/j.aap.2009.09.025.

36. World Road Association, 2015. Road Safety Manual: a manual for practitioners and decision makers on implementing safe system infrastructure. Retrieved at http://roadsafety.piarc.org/en.

37. Aarts, L.; van Schagen, I. Driving speed and the risk of road crashes: A review. Accident Analysis and Prevention 2006, 38, pp. 215-224, https://doi.org/10.1016/j.aap.2005.07.004.

38. Hauer, E. Speed and Safety. Transp. Res. Rec. 2009, 2103, pp. 10-17, https://doi.org/10.3141/2103-02.

39. Montella, A.; Persaud, B.; D'Apuzzo, M.; Imbriani, L.L. Safety Evaluation of an Automated Section Speed Enforcement System. Transp. Res. Rec. 2012, 2281, pp. 16-25, https://doi.org/10.3141/2281-03.

40. Montella, A.; Punzo, V.; Chiaradonna, S.; Mauriello, F.; Montanino, M. Point-to-point speed enforcement systems: Speed limits design criteria and analysis of drivers' compliance. Transport. Res. C-Emer. 2015, 53, pp. 1-18, https://doi.org/10.1016/j.trc.2015.01.025.

41. Montella, A.; Imbriani, L.L.; Marzano, V.; Mauriello, F. Effects on speed and safety of point-to-point speed enforcement systems: evaluation on the urban motorway A56 Tangenziale di Napoli. Accid. Anal. Prev. 2015, 75, pp. 164-178, https://doi.org/10.1016/j.aap.2014.11.022.

42. Montella, A., Imbriani, L.L. Safety performance functions incorporating design consistency variables. Accid. Anal. Prev. 2015, 74, pp. 133-144, https://doi.org/10.1016/j.aap.2014.10.019.

43. Neuman, T.R.; Slack, K.L.; Hardy, K.K.; Bond, V.L.; Potts, I.; Alberson, B.; Lerner, N. NCHRP Report 500: Guidance for Implementation of the AASHTO Strategic Highway Safety Plan: A Guide for Reducing Speeding-Related Crashes, vol. 23. Transportation Research Board, Washington, D.C., 2009.

44. Montella, A.; Andreassen, D.; Tarko, A.; Turner, S.; Mauriello, F.; Imbriani, L.L.; Romero, M. Crash databases in Australasia, the European Union, and the United States: review and prospects for improvement. Transp. Res. Rec. 2013, 2386, pp. 128-136, https://doi.org/10.3141/2386-15.

45. National Highway Traffic Safety Administration. MMUCC Guideline: Model Minimum Uniform Crash Criteria, Fifth Edition. U.S. Department of Transportation, Report DOT HS 812 433, Washington, D.C., 2017.

46. Masoud, A.; Lee, A.; Faghihi, F.; Lovegrove, G. Building sustainably safe and healthy communities with the Fused Grid development layout. Can. J. Civ. Eng. 2015, 42(12), pp. 1063-1072, https://doi.org/10.1139/cjce-2015-0086.

47. Montella, A. Identifying crash contributory factors at urban roundabouts and using association rules to explore their relationships to different crash types. Accid. Anal. Prev. 2011, 43(4), pp. 1451-1463. https://doi.org/10.1016/j.aap.2011.02.023.

48. Montella, A. Roundabouts. In Safe Mobility: Challenges, Methodology and Solutions, Lord, D. and Washington, S. (Ed.), Emerald Publishing Limited, UK, 2018, (Transport and Sustainability, Vol. 11), pp. 147-174, https://doi.org/10.1108/S2044-994120180000011009.

49. Montella, A.; Turner, S., Chiaradonna, S., Aldridge, D. International Overview of Roundabout Design Practices and Insights for Improvement of the Italian Standard. Can. J. Civ. Eng. 2013, 40(12), pp. 1215-1226, https://doi.org/10.1139/cjce-2013-0123. 
50. Rodegerdts, L., Bansen, J., Tiesler, C., Knudsen, J., Myers, E., Johnsonm, M., Moule, M., Persaud, B., Lyon, C., Hallmark, S., Isebrands, H., Crown, R.B., Guichet., B., O'Brien, A. Roundabouts: An Informational Guide, Second Edition. Transportation Research Board, NCHRP Report 672, Washington, D.C., 2010.

51. Nabors, D.; Gibbs, M.; Sandt, L.; Rocchi, S.; Wilson, E.; Lipinski, M. Pedestrian Road Safety Audit Guidelines and Prompt Lists. U.S. Department of Transportation, Federal Highway Administration, Office of Safety. Report No. FHWA-SA-07-007, Washington, D.C., 2007.

52. CROW. Design manual for bicycle traffic. Ede, The Netherlands, 2017.

53. Federal Highway Administration. Separated Bike Lane: Planning and Design Guide. U.S. Department of Transportation, Report No. FHWA-HEP-15-025, Washington, D.C., 2015.

54. Massachusetts Department of Transportation. Separated Bike Lane Planning \& Design Guide. Boston, MA, 2015.

55. National Association of City Transportation Officials. Urban Bikeway Design Guide, Second Edition. New York, NY, 2014.

56. Montella, A.; Aria, M.; D'Ambrosio, A.; Mauriello, F. Data Mining Techniques for Exploratory Analysis of Pedestrian Crashes. Transp. Res. Rec. 2011, 2237, pp. 107-116, https://doi.org/10.3141/2237-12.

57. Montella, A.; Aria, M.; D'Ambrosio, A.; Mauriello, F. Analysis of powered two-wheeler crashes in Italy by classification trees and rules discovery. Accid. Anal. Prev. 2012, 49, pp. 58-72, https://doi.org/10.1016/j.aap.2011.04.025. 